$$
\text { 6. }
$$

J. Plimks escilbents

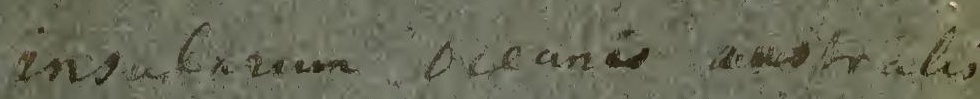

$$
1786
$$


Dofocm:

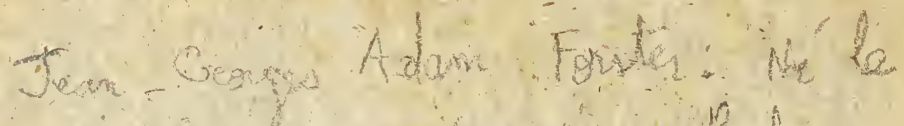
29 pata 1054 a Namenthetion not to 12 Jemen 1794.

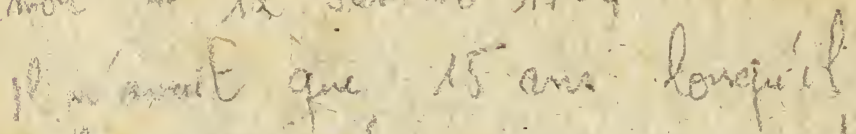

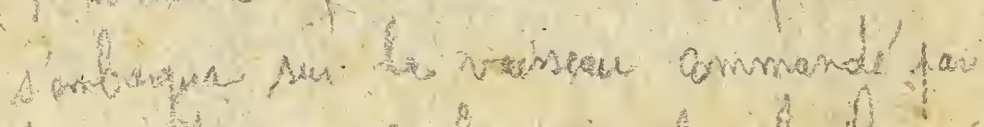
L captaine ecak, ave loquel $d$ fil $t$ than de namde.

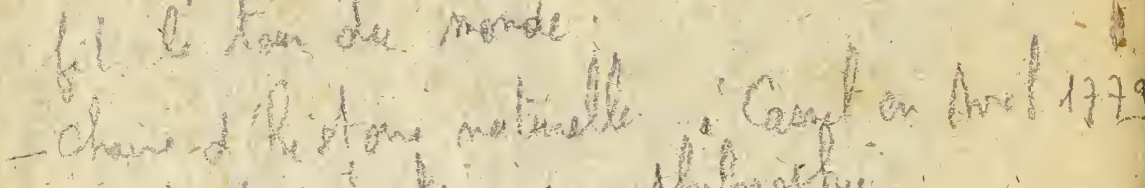

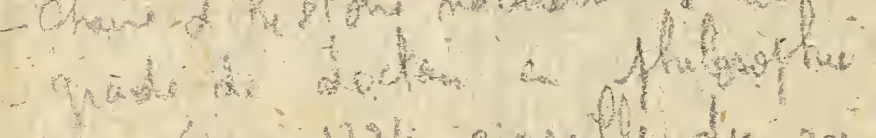

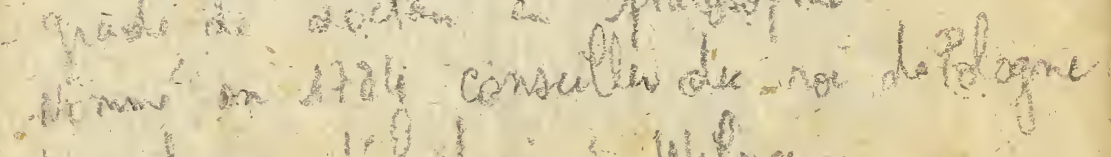
at todpis of hathe a Wha.

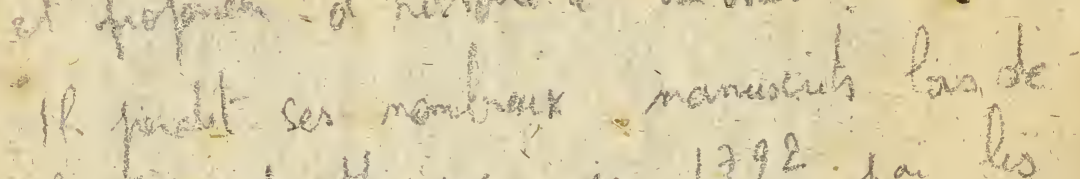
la prise de Maytenge in 1792 fai lis

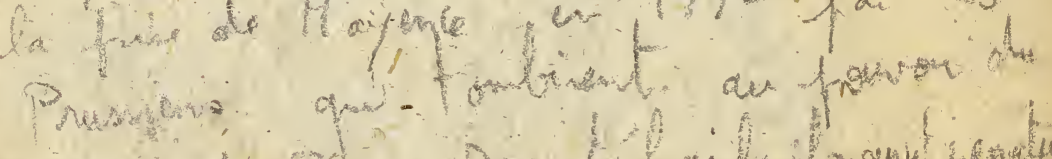

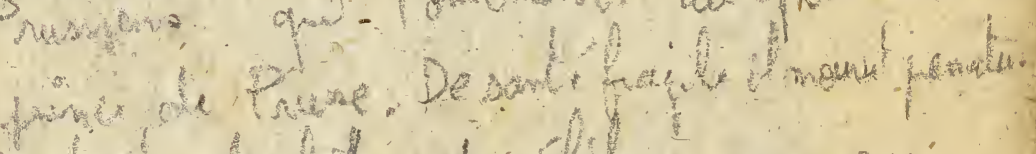

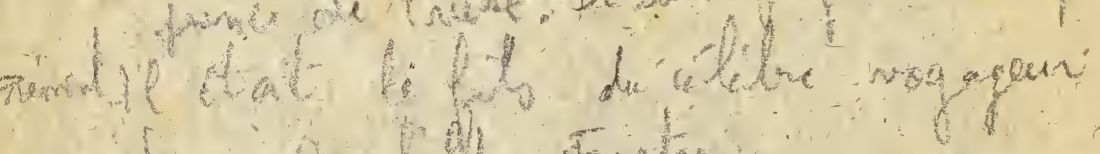
Sean Rearde Fontor.

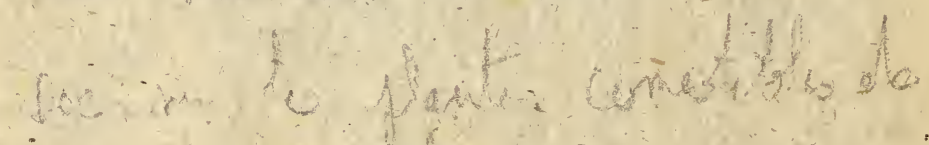




\title{
GEOPGII FORSTER,
}

MEDIC. DOCT.

SERENISS. POLONIAE REGI A CONSIIIIS

INTIMIS, ETC.

DE

\section{PLANTIS ESCVLENTIS}

\author{
INSVLARVM OCEANI AVSTRALIS
}

\section{COMMENTATIO BOTANICA.}

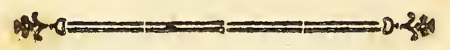

Sed primum pofitum fit, nosmet ipfoș commendatos effe nobis, primamque ex natura hanc habere appetitionem, यद confervemus nosmet ipfos.

Crc. de finib. bore. et mal. L. IV.

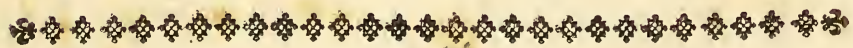

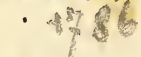

BEROLINI,

APVD HAVDE ET SPENER, $M D \in G I X X V I$.

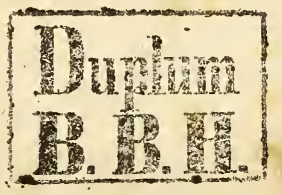


6. Foroter. $\quad k$ yte num the

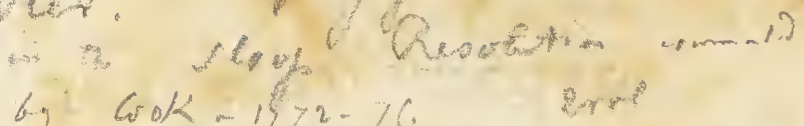

b. $\cos \alpha-13>2-76$

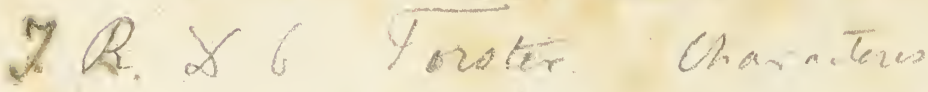

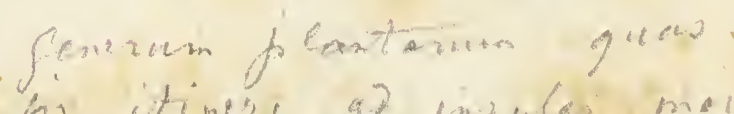

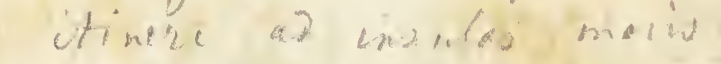
aleb. (i) fiect

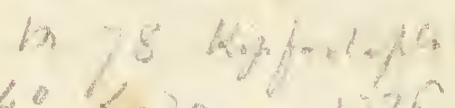

$40 \operatorname{trmin} \times 1) 6$

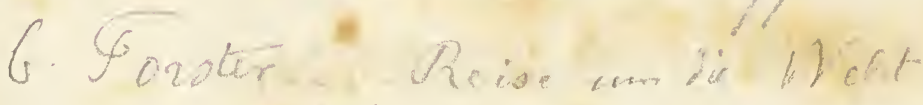

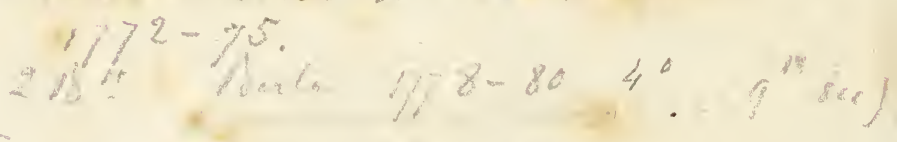

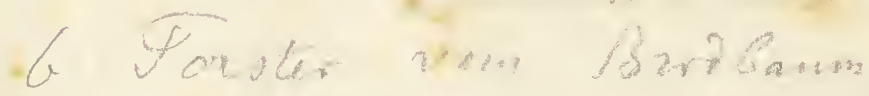

$$
\text { mit } 2 \text { Korft. } 40.1784
$$




\section{VIR O}

\section{ILLVSTRI ET GENEROSO}

\section{IOANNI ANDREAE}

\section{V R R A Y,}

ERVITI ORDINIS DE WASA, CONSILIARIO REGIAE AVLAE, PROFESSORI MEDICINAE ET BOTANICES IN ACADEMIA REGIA GOETTINGENSI, REL。

$$
\text { BOTANICO }
$$

NOSTRI AEVI PRIMARIO

H V N C

DELECTVM FLORVLAE AVSTRALIS

PIENTISSIME CONSECRAT GEORGIVS FORSTER。 



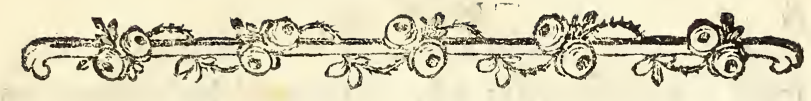

\section{PRAEFATIO:}

A

fiam inter orientalem et Americam zea ftralis, omnium vaftiffimus nullis extra zonam torridam, praeter unicam fere novam Zeelandiam, terris interceptus; intra tropicos autem plurimis infulis, veluti punctis confperfus, quarum aliae in congeries aliquot collectae, aliae majori fpatio disjunctae jacent. Verfus occidentem inde a decimo quem vocant latitudinis auftralis gradu usque ad quadragefimum quartum, idem oceanus novam Hollandiam, Europa maiorem, alluit.

Incolae harum terrarum alii candidiores funt, alii nigricantes. Priores numero reliquis praeftant, uno eodemque fermone utuntur, morumque fimilitudine, quantum pro climatum diverfitate licuit, inter fe conveniunt. Ex Indiae regionibus orientalibus per archipelagum moluccanum atque philippinas infulas in oceanum auftralem eosdem migrafe, propter analogiam linguae eorum vernaculae cum ma- 
laica, certifimum eft. Oceani huius partem borealem, tropico tamen inclufam, tres infularum congeries occupant, Latronum guse et Marianae dicuntur, Carolinae, et noviffimo Cookii itinere detectae $\mathbf{S}$ andvigiae. In ea parte quae trans aequatorem ad auftrum fita eft, totidem archipelagis, Amicorum fcilicet. Societatis et Marchionis Miendozae, fedem figerunt; quibus adnumerari debent infulae illae, hinc atque illinc in oceano difperfae cuius fuperficiem vix fuperant, ftupendis lithophytorum habitaculis inaedificatae, nobis demerfae (Low Iflands) dicendae. Eiusdem ftirpis porro ramentum extra tropicum auftralem, verfus americae littora in pafchali infula reperitur (Oftereiland) aliud deinceps ex oppofito novae hollandiae nova Zeelandia eft, inde a tricefimo quinto ad quadragefimum feptimum latitudinis gradum protenfa.

Nigrae gentis longe alia ef ratio; nam in Indiae archipelagis orientalibus, et praefertim in montuofis fylvaticisque infularum latibulis agreftium hominum familiae reperiuntur, quae forte cum hisce auftralioribus nigritis ex eadem ftirpe prognatae funt. Eiusdem gentis praecipua fedes eft illa infularum congeries, quae aequatori et moluccanis infulis proxima, $\mathrm{Pa}$ puae five novae Guineae, Britanniae, Hiberniae. que nominibus in tabulis geographicis defignari folet. Inde per infulas Charlottae, novasque Hebrides ad novam Caledoniam usque haecce nigritarum proles videtur penetraffe, breviffmo certe, fi cum eo conferatur, quo candidiores illi homines novam $\mathbb{Z}$ eelandiam et extremam 
mam pafchatis infulam petierunt, itinere, et a primis fedibus minus remoto. Nigri huius populi forte foboles, etiam novam Hollandiam occupavit, licet hoc certo affirmare non aufim; quod fi vaftiffimae iftius regionis incolae re vera originem trahunt a Papuanis, dandum id quoque eft, eos a climate et carnium efu aliquanto immutatos fuife. Verum enim vero nigrorum hominum in hisce terris in primis ea eft fingularicas, ut fere in qualibet infula, licet proxima vicinitate cum reliquis coniuncta fit, proprio diverfifimoque fermone utantur; totque paene fint idiomata, quot funt infulae $a b$ iisdem habitatae. Quo quidem argumento nullum exquifitius immanitatem maiorum, a quibus ortum trahunt comprobare videtur; et enim quis eft, qui indomitam feritatem fimul et infcitiam climatis ubertate altam in eo potiffimum non agnoscat, quod praeter vilus parandi rationem, nihil a parentibus didicerint, defertisque laribus etiam patrii fermonis obliti fint?

Singularem hanc diverfitatem inter Auftrafiae vel Polynefiae populos, cum iam neque aëris, qui omnibus idem propemodum eft, neque alimentorum, quibus omnes fere iisdem vescuntur, diverfae qualitati tribuenda fit, originem ducere a primitiva autochthonum varietate arbitror. Indelebilis enim et tanquam inufta fpecies, diverfis hominum familiis inhaeret, plurimis notis charadterifticis infignis, quae et climati omnimodo refiftit, et ciborum commutatione non frangitur, nec non perpetua fucceffione, nifi contaminatae fuerint generati- 
ones aliqua mixtela, a parentibus ad ultimam prolem integra meraciffimaque defcendit. Cui affertioni ne teftimonia defint ex aliis regionibus deprompta, verbo faltem tetigiffe fufficiet aethiopum five nigritarum e propriis fedibus africanis in peregrina climata translatorum generationes, atro colore, crilpa in capite lana, porrectis maxillis, nafo fimo, (abis turnidis, ceterisque indiciis ab optimo Soemmerringio, fummo incifore, mihi $\left(^{*}\right)$ nuper enumeratis, atevis femper fimillimas. Attamen de origine harum in genere humano varietatum aliquid certi vel ea ratione confitui nequit, quod in univerfum hiftorica traditione antiquiores fint, et ludaeorum oracula, quibus Europaei e confuerudine piè affentiuntur, de iisdem fileant. Cum autem ludaeos femel in fcenam evocaverim, eosiem non dimittendos judico, priusquam eorum exemplo varietatum humanarum perfiftentiam firmaverim. Plurima enim fecula non fuffecerunt ad abluendam iftam notam vultui horum hominum adeo profunde infculpram, qua vel a primo intuitu afraticam eorundem originem, meridie clarius perfpectam habemus.

Quod ad climatis temperiem attinet, illud nimirum in novae Hollandiae defertis fiticulofis, inter calidifima jure referri poteft, neque huius parti boreali, aequatori vicinae, ipfam africam aequinoctialem aeftuofiorem exiltimarem. Infulas vero, per oceanum difperfas, ven-

(*) Ueber die körperliche Verfchiedenheit des Negers vom Europäer. Frankf, u. Mainz 8. 1785. 
ventorumque intra tropicos perennium halitu perflaras fáluberrima et amoeniffima coeli temperie gaudere, navigatores quotquot ad easdem appulerunt omnes une ore pronunciant. Novae Zeelandiae, licet frequentibus procellis ex agitetur alpesque fuas perenninive obrutas in altum adtollat, nihilo tamen fecius leniores funt brumae, cum in eius parte extrema ad quadragefimum quintum usque gradum latitudinis in auftrum converfa, fub ipfo fine autumni herbas et frutices florentes legiffem.

Qui Carolinas, Marianas, Sandvigias, Mendocinas, Societatis et Amicorum infulas tenent, primae gentis homines, elegantioris funt formae, colorisque puriffimi caltanei absque ullo nigredinis inquinamento. Statura eorum mediocris eit, ad proceritatem accedens; ca. pilli longi, denfi, cincinnati, nigri; barba maribus crebra, prolixa; oculi ampli, iride nigrofusca; nafus latiusculus, nec fimus; labia crasfciuscula, dentes pulcherrimi. Magnates colore faepius lucidiore dignof́cuntur, corpore proceriore, robufto, obefo, abdomine ampliffino. Sed exceptionem habent infulae aquae penuria laborantes $\mathbb{E}$. uwa, Tonga, Namoka, Pafchatos, quarum incolae, etiam natu principes, plerique gracilioris funt formae.

Ingenium horum hominum mite, morum comitate quadam et manfuetudine coniunctum, at in bellis in faevam ferocitatem degenerat. Respublica omnibus feudalis eft, regis moderamini fubieeta, cuius in amicorum infulis nullo limite circumfcriptam poteftatem, in focietatis 
archipelago potentiores vafalli coèrcent. Vulgus hominum clientibus conftat, et mancipiis glebae adfcriptis, regiturque polytheismi fuperfticione, quae in Sandvigiis praefertim infulis profundiores videtur radices egiffe, verum etiam apud Taheitenfes interdum humanas vic. timas erogat. lis in univerfum monogamiae confuetudo, vix a nobilibus, militibusve fpreta. Verimentorum genus laxum, leve, climati accomodatum; balneum frigidum bis de die, matutinum et vefpertinum; unguentorum ufus inprimis inter magnates frequens; moderata in laboribus domefticis exercitatio; noeturni aëris intemperies fedulo evitatur; mollis denique libido, rifus, joci, fabulae, cantilenae et faltationes ad tuendam fanitatem vitamque ad ultimum terminum protrahendam conferre videntur.

Victus ratio, apud hancce gentem quam fit congrua valetudini robuftae et integrae, videndum eft. Artocarpi fructus farinaceo-pulpofi ab Otaheitenfibus, infularumque Societatis, Mendocinarum, Sandvigiarum, Carolinarum et Latronum indigenis loco panis adhibentur, primis odo menfibus in anno maturefcentes, fed tamen ante maturitatem perfedam in cibum cedunt. Hi decorticati, folisque obvoluti, in fornace fubterranea per horulam aflati, comeduntur. Reliquis quatuor menfibus mufae inprimis fruetus, radicesque ari, diofcoreae, dracontii, taccae, convolvuli, hominibus cibum fuppeditant: quem ter fingulis diebus capiunt, plerumque refrigeratum, incerdum tepidum, nunquam vero ferventem. Artocarpi fructum, 
quem blando alimentorum vegetabilium generi adnumerari non dubitem, variis modis praeparatum, five acidulatum fermentatione, five cum oleo et nucleis cocos nuciferae commixtum frixumque magnates quidem in deliciis habent, fed eidem lautiores quoque epulas adjiciunt; pisces enim fapidifimos, pullos gallinaceos, porcinas, caninasque carnes in conviviis magna quantitate ingurgitant. Horaeis porro fruEtibus Spondiae, Mufae, Eugeniae crudis fubinde vefcuntur.

Sale marino in littore radiorum folarium ope concreto in Sandvigiis infulis ad cibos faliendos utuntur. Societatis infulae fale concreto carent quidem, fed eius loco aqua oceanica pro embammate adhibetur; in parchatis demum infula, nimis arida et aqua pura omnino deftituca, non raro falfam pro potu ordina. rio hauriunt. In Marchionis, Societatis, Sandvigiisque infulis fcaturigines aquae frigidulae, purifimae, levifimae abundant, communique ufui inferviunt. Qui delicatius vivunt, lympham nucibus cocos inclufam forbillant. Sacerdotum autem turba et magnates extractum radicis piperis methyftici potant, quod non folum toxicis viribus eosdem inebriat, fomnoque gravi opprimit, fed etiam corpus lente emaciac, et leprae obnoxium reddit. Abominandum hocce temetum in amicorum infulis praefertim uftatiffimum eft Ibidem plurium caufarum jundta operatione plane efficitur, ut homines, ex eadem firpe cum Taheitenfibus er Sandvigianis prognati in univerfum tamen minus robufti evadant, eorumque proceres non adeo pin- 
pinguescant, fanguinis autem acrimonia maiore laborare videantur; unde vel elephantiafin, vel totius corporis fqualidiffimam purulentamque exulcerationem non raro generatam fuiffe novimus. Quum enim huius archipelagi auftraliores infulae, fontibus et rivulis aquae purioris penitus careant, incolis fuis non folum potum falubrem, fed etiam balnea in climate aeftuofo maxime falutaria denegant. Deinde, quod forte maximi momenti eft, blandiffimi ar. tocarpi fructus ibidem rarius occurrunt, atque radices jam commemoratae ari, dioscoreae taccae, huius alimenti faluberrimi vices agunt, quae licet coEura vel toftione a volatili et fere deleteria caufticitate liberentur, tamen adftringentium et acrium indolem non ita plane exuunt, ut fufpicionem movere omnino non. valerent, apud homines iisdem perpetuo altos tandem maffam fanguinis et humorum exacerbari, nimiaque acredine accendi poffe. E contra vero blandiori diaeta, horaeisque fruetibus aquofis ufi taheitenfes, aquae potatores, quorum corpora crebris ablutionibus humeEtantur et emolliuntur, non poffunt non obefiores reddi, cum revera fucci corporis humani tot diluentium juncta aEtione nimis debilitarentur, nif tranfpiratio in regionibus calidioribus abundantior, phlegma fuperfluum tolleret.

Sunt qui climatis influxum in res humanas pertinaciter negant; ii Novam 'Zeelandiam vellem adeant, cuius regionis incolae cum Taheitenfibus et indigenis archipelagi Amicorum fermone conveniunt, cum quibus etiam fabulae 
religiofae, et traditiones, nec non ipfe vultus et color communem iisdem originem fuiffe teItantur. At profecto maximam inter hasce gentes ortam a climatis neceffitate morum diverfitatem mirarentur. Primi enim novae Zeelandiae coloni, qui ad huius regionis oras boreales appulerunt, faccharatum licet convolvulum chry forrhizum, radicesque ari et diofcoreae Iecum attuliffent, piscaturae tamen, quae facilem commodamque viltus rationem iisdem pollicebatur, fefe addixerunt; horticulturam, prout operofior erat, fenfim verfus auftraliorem extremitatem terrarum errabundi prorfus deferuerunt. Quare fingulis familiis infulam pervagantibus et $a b$ invicem fegregatis, cum jam nullo focietatis vinculo amplius compefcerentur, ad libidinofam ferocitatem patebat re. ditus. Incertus enim pifcaturae proventus eas frequenter loco migrare coëgit, ut victui profpicerent; hinc inter diverfas familias, quotiescunque fame perductae in idem littus pifcofum efcendiffent, de Littorum dominio acerrime dimicatum eft. Apud victos inde pariter ac viEtores irata fames aluit inimicitiam, animos. que fibi invicem infenfiores reddidit. Eo ufque tarialem vindictae cupiditas apud irritabile illud et iracundum genus hominum invaluit, ut etiam in occifos hoftes dentibus faevire affueverint. Cum igitur bellicam virtutem et fortitudinem maximi faciant, neque cuiquam honorem habeant, nifi corporis viribus plurimum polleat, hinc iniquam et vere tyrannicam in fexum fequiorem poteftatem exercent; quin fpretas ac defpectas uxores non folum ad vilifima, eaque moleftiora officia adi- 
gunt, fed et matrem feptennes pueri impune conviciantur aut fcelefta manu feriunt.

Corpus a frigoris iniuria pannis e phormio textis, plumisque avium aut pelle canina munitis tuentur Sed igni circumiacentibus intra fumofa tuguria munditiae nulla cura eft cum $a b$ omni lavatione fqualidi atque pediculofi $a b$ horreant, nec non pigmento rubro et oleo rancido vultum foedare confueverint, ut hoftibus terrorem injiciant. Viltus, quemadmodum fuperius monui, praecipuus pifculentus eft, pifcibus enim et recenter captis, et ad folem exficcatis vefcuncur. Docuit tamen etiam dira neceffitas ad fylvas confugere, filicumque radices medulla farctas effodere, dum vexatum procellis

\section{atrum}

defendens pisces hiemat mare.

Harum filicum in borealiori infula, quae populofior eft, cumingentes acervos collectos vidiffet $\mathrm{Cl}$. Crozet, fimulque comperuifet radicum Convolvuli, ari et diofcoreae culturam ibidem non plane negligi, hominibus Novae Zeelandiae victum vegetabilem efle nimis feftinanter inde collegit. Idem navarchus experientifimus apud incolas iftius regionis frequentem gummi cuiusdam calefacientis comiffatio. nem obfervavit. Neque iam recufo, in calidiore Novae Zeelandiae parte, advenas e Z0. na torrida homines confuetudinem vegetabilis alimenti confervafe; quin potius libenter concedam, hoc ftabili et minus erratico vitae genere effectum fuiffe, ut numerus eorum magis 
accrefceret, civitatifque et regiae poteftatis primordia ibidem una progerminarent. Verum ex autoptarum confenfu facile colligitur, barbaros in boreali Novae Zeelandiae parte horrido carnium humanarum adpetitu, ferociffimo in hoftes animo, ad vindictam iramque pro. clivitate non folum auftraliores familias, mereque ichthyophagas aequare, fed et tanto isdem praeftare, quanto in univerfum viribus corporis membrorumque immanitate eas antecellant. Qui ciborum ad animi adfeetus excitandos potentiam agnofcunt huius tantae ferocitatis ftimulos forte $a b$ alkalefcente pifcium fubftantia petant, cum etiam in temperatiore infula, pifces faltim ex parte, hominum nutrimento infervire noverint.

Similem huic differentiam, quae inter diverfas nigrae gentis colonias intercedit, breviffimis verbis expediam. Ex his, qui Novae Caledoniae infulan aridam et montuofam incolunt homines reliquos manfuetudine pacifque ftudio fuperare videntur, Statura iis aliquanto procerior, color fufcus quidem, fed ad caftaneum vergens: capilli torti, nec tamen plane ut in aethiope lanati. Eorum arva plantationi radicum ari et diofcorea idonea, in regione littorali, aquis marinis ftagnantibus fubinundaca et rhizophorae, ficuumque radicantium denfo frutice intercepta, ligonibus fedulo confodiuntur. Soli fterilitas autem improbum incolarum laborem parce nimis remuneratur; quare et pifcatu vitam fuftentant, et ad fylveftria fuccedanea e regno vegetabili recurrunt, corticesque infipidos hibifci tiliacei exfugunt. Novarum 
Hebridum contra foecundifima tellus eft, quas fcilicet calor intertinus vulcani non folum refocillet, fed et late difperfus laetificet cinis. Ibidem hortuli, quos indigenarum induftria plantavit, intra fpiffum undique nemus abfconditi latent, Mufae inprimis fructibus citro, ficubus edulibus, nucum vario genere, tum etiam ari et diofcoreae radicibus divites. Ipfa hinc inde farinofis onufta fructibus artocarpus, licet minus frequens, confpicitur; domefticae porro volucres fuumque greges circa domicilia vagantur. Succurreret cuiquam forte illam naturae altricis ubertatem intuenti, ut in hisce infulis hominum ftirpem bene faginatam, corpulentam, fegniorem, imbellem, pacisque et veneris, otio quae maxime aluntur, artibus deditam exfpeEaret. Enimvero miraretur quod citra fpem illi obviam fierent (praeprimis in Malicollo infula) nigerrimi homunciones, nafo fimo, angulo Camperi acutiore $\left({ }^{*}\right)$, capillitio crifpo et lanato, exiles, macilenti, deformes, nudi, cingulo armillisque ftrietifimis coaretati, garruli, ingeniofi, aftuti, hiftriones, agiliffimi, irrequieti, fufpiciofi, trepidi, fagittis clavisque perpetuo armati, mulierum ofores, anthropophagi! Quod vero infulae Tannae indigenis contigerit, mallicollenfibus ingenio magis mitescere, eosque proceritate corporis artuumque masculo vigore fuperare, id procul omni dubitatione, familiari quam habene cum quadam albidae gentis colonia confuetudini tri-

*) Ex occurfu linearum, alteritis ab offe frontali, alterius a meatu auditorio, ad dentes incifores fuperiores, duetarum. 
tribuendum eft. Nam praeter vernaculam fu$\mathrm{am}$, intelligebant etiam linguam focietatis et amicorum infulis conmunem, eamque ulcra proximam infulam irronan, in alia, cui nomen Itonga, in ufu effe nobis referebant.

Haec praemittenda mihi videbantur, cum adumbrationem plancarum molitus effern, quae ad rem cibariam in terris auftralibus pertinent; neque iniucundum hunc introitum, nec prorfus inutilem ratus, qui etin nova et inaudica non proferat, cerris tamen et fide dignis obfervationibus doetrinae utiliori miniftret. Equidem mihi videor illorum opinionem rede amplexum effe, qui maximam inter hominum familias diverfitatem organicam, ab ipfo generationis typo derivandam, morumque notas characteriticas, et confuetudinum perpetuitatem imitatione maiorum oriundam exiftimant; climati tamen aliquid virium ineffe ad infleetendos animos non omnino recufant. Sed etiam in cibi potusque diverfis generibus, non folum corporis humani fabricam ingulariter renovandi immutandique, verum ipfiusmet animi energiam excitandi aut demulcendi vim fane maximam delitefcere, celeberrimi nominis viri ftrenuis argumentis demonftrare conati funt. Famis enim fitisque dolore follicitaros homines, ut detritas de corpore particulas novis fupplementis refticuant, diluantque fanguinem motu naturali fpifatum, alkalefcentem edulcorando reftaurenc, ex deglutitis et in ventriculo folutis corporibus organicis paratum fuccum tubulis villofae tunicae fufceptum, et in glandularum plexibus demum affimilatum, venis hau- 
rire quidem, eoque machinam animalem perpetuo refarcire, fed pro diverfa principiorum in alimentis mifcela diverfifimum profeeto habitum nancifci afferuerunt, cujus etiam in fenfus internos reactionem manifeftam fimili racione contingere arbitrati funt, qua mutato infrumentorum mechanismo, effectuum difcrimina in operibus humano artificio elaboratis plane deprehenduntur. Adduxerunt in huius doctrinae defenfionem exempla morborum vas rii generis, quorum fons et origo fublato elementorum noftri corporis aequilibrio debetur, fanandorum autem ratio in eodem mutata diaeta adhibitisque remediis efficacibus refticuendo confifit. Tum in medium porro protulerunt animi affectus hoc vel illo cibo potuve interdum fopitos aut exfufcitatos; nec non denique inter tot gentium diverfifima ingenia, mitiffimum phytiphagis, atrox et bellicofum fola carne vefcentibus tribuerunt. Cum autem fingula, quibus haec opinio fulciri folet argumenta. poit Hallerum denuo recenfere $\left({ }^{*}\right)$ fupervacaneum et citra huius opellae propofitum foret, id unum, miffis coniecturis fallacibus adiiciam, ad immutandum typum varietatum humanarum, ex obfervationibus fuperius enumeratis, non adeo notabilem effe in terris auItralibus ciborum efficaciam.

Plantae in oceani auftralis infulis efculentae quinquaginta quatuor in univerfum mihi innotuerunt, quarum viginti fex ante noftrum iter botanicis incognitae erant. Harum univer-

(*) Phyfiolog. Tom. VI, Lib. IX. See. 3. 
verfalifimae funt, (cum etiam extra tropicos reperiantur, ) Convolvulus chryforrhizus, Diofcorea alata, Arum macrorhizon et efculentum; his proxime accedunt, tropico ta. men inclufae: Mufa paradifiaca, Cocos nucifera et Artocarpus incira; reliquae omnes in una alterave infularum congerie defiderantur, aut minus frequentes funt. Numeravi porro in Sociecatis infulis pecies efculentas viginti fex; in amicorum infulis totidem; fed nonnullas diverfas; in nowis Hebridibus circicer viginti; in nova Zeelandia ledecim, quibus comprehenduntur antifcorbuticae feptem Europaeis quidem pretioffirmae, fed quarum apud inco. las ad rem cibariam nullus eft ufus.

Erunt forte, qui in tenui laborem me collocaffe exiftiment. Attamen non defuit, qui ex hac tenuitate oriundam gloriolam legitimis dominis praeriperet, et alienae meffi immiteret falcem $(*)$. Taceam rerum naturalium co. $\mathrm{B}_{2}$

gnia

(*) Dederat in parer optimus, flagitantiamico, ut aliquot centurias plantarum ex linere relatarum, magni nominis viro er no lo non montes anri pollicenti, ea tamen lege arque omine, dono concederet, ne iis quisquam utererur, ad defcriptiones ex ficcis fpea ciminibus paran as; quum frilicet easdem Pater et Ego juncta o era evulgare nobis propofuifimus. Verum in Supplemenzo Plantarum Syfematis Vegetabilio am a CAROLO a LIN R Filio Brunsvigae 178. C. dito, in qualiber pagina plantis Oceani Pacifici, Bo. tanophili miratur tam nunc nomen Equitis $B A E C x_{2}$ adfcriptum; qui nunquam hoc mare adiit

Sic Vos non obis

Hos ego verficulos feci, tulit alier honoren! 
gnitionem, ufu femper effe anteriorem; et earum quae noftro itinere innotier ant ad $h$ mi num neceffitates adplicationem, etiamfi parte faltem aequalibus noftris contingat, pofteritati tamen clariffime perfpiciendam demum re. fervari.

Quod reliquum eft, quemadmodum adverfaria mea rurfus evolventi grata mihi erat abfoluti peripli commemoratio, ita fpero, mi lector, defcriptiones fequentes botanicas et tibi aliquam voluptatem allaturas, qua mecum gaudeas fruarisque.

\section{D tum Vilnae Lithuanicae, anno MDCCLXXXVI。}

D. GEORGIVS FORSTER. 


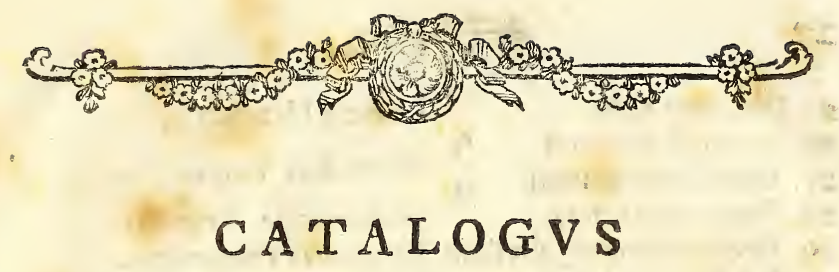

PLANTARVM ESCVLENTARVM

AVSTRASIAE。

I. Fructus.

Nomina

1. Artocarpus incifa

2. Mula parad fiaca

3. Sprondias dulcis t

4. Citrus turantium.

5. Citrus decumana

6. Lugenia malaccenfis

7. Fi us afpera t

8. Ficus granatum $t$

9. Ficus indica

10. Pandanus odoratiflima

II Morinda citrifolia

12. Solanum aviculare $t$

13. Achras diffeeta

I4 Crataeva religiofa t

I5. Coriaria farmentofa to

\section{Claffes}

Monoecia Monandris.

Polygamia Monoecia.

Decandria Pentagynia.

\}olyadelphia Icolandria.

?

Icolandria Monogynia.

Polygamia Trioecia.

Dioecia Monandria.

Pentandria Monoginia.

Hexandria Monogynia. Dodecandria Monogynia. Dioecia Decandria.

2. Nuces.

16. Cocos nucifera

37. Corypha umbraculifera. $\}$ Appendix Palınae.

I8 nocarpus edulis

Decandria Monogynia.

19 Terminalia Catanpa ? Polygamia Monoecia.

2I. Maba major t

22. Sterculia Balanghas.

23. sterculia foetida

Dioecis Triandria.

j. Monoecia Monadelphia.

3. Radices.

24. Convolvulus chryforrki- Pentandria Monogynia. zus to

B 3 25. 
25 Diofcores alata

26. Arun ef ulenum

27. Arum macrorhizon

28. racca pinnasifida
Dioecia Hexanciria.

j Gynandria Polyandria

Dodecandria Frigynia.

29. Dracontium polyphyllum Gynandria Polyandria. 30. Dgidgi ? radices

32. Dracaena terminalis. Hexanơria Monogynia.

4. Olera.

33 Draeaena indivifa to

34. Arec oleracea?

35. Areca fapida †

36. Apium graveolens

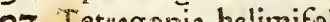

37. Tetugonia halimifolia of

38. iepdiun olersceum $t$ ?

39. Lepidium Rifeidium 5

40. Sonchus oleraceus

41. Boerhaavia erecta

42. Solanum viride of

43. Portulaca lutea to
Hexandria Monogynia.

f Appendix Palmae.

Pentandria Digynia.

Icofandria Pentagynia.

Tetradynamia Siliculofa

Syngenefia P. aequalis.

Monandria Monogynia.

Pentandria Monogynia

Dodecandria Monogynia.

\section{Succedanea.}

44. Avicennia refinifera to Didynamia Anuiofpermia.

45. Hihifcus tiliaceus

46. Coix Lacryma

Monadelphia Polyandria

47. Pteris efculenta $t$

48 ?olypodium medullare $t$

49. Polypodium dichoto

mum

Monoecia Triandria.

Cryptogamia Filices.

\section{Potulenta.}

50. Piper methyfticum + Diandria Trigynia.

5I. Sacchurum officinarum Triandria Digynia.

52. Convolvalus Turpethum Pentandria Monogynia.

53 Melaleuca fcoparia Icofandria Monogynia.

54 Dacrydium cupreffinum to Dioecia.

Signo t notatae in editione XIV. Syrtematis Vegetabilium Linnaei, qua cura Cel. Io. Andr. Murrayiprodiit, non regeriusirus. 


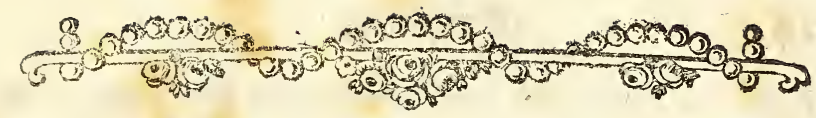

\section{Plantae Efculentae}

\section{Infularum Oceani Auftralis.}

\section{I. \\ F R V C T V S.}

I. Artocarpvis incisa. F.

A foliis incifis. M. S. V. p. 838. (Monogr. mea: vom Brodbaum 4to I784).

Arbor craffitie hominis, altitudine quadraginta pedum et ultra, trunco ereeto, ligno molliori, levi, flavicante; libro efibrillis rigidiufculis reticulato, albo; cortice laevi, rimofo, pallide cinereo tuberculis exiguis raris afperfo. Arboris partes laefae omnes liquorem fundunt glutinofum lacteum.

Rami in comam amplam fubglobofam faftigiati, inferiores longiores, diftantia decem five duoB 4 decim 
decim pedum fupra terram e trunco prodeunt, fere horizontaliter patentes, fparif, fubverticillati. Ramuli adfcendentes, apice floriferi, fructiferique.

Folia alterna, petiolata, ovata, fupra medium in lobos feptem novemve lanceolatos acutos profunde diffecta, finubus rotundatis; caeterum integerrima, utrinque glabra, laevia, patentia, laete virentia, fubtus pallidiora, membranacea, fesquipedalia, undecim pollices lata, venofa, nervis craffis, numero loborum e rachi communi excurrentium. Folia juniora ficut partes omnes teneriores arboris tactu glutinofa funt.

Petioli teretiufculi, laeves, adfcendentes, bipollicares. Stipulae binae, folia juniora involyentes, lanceolatae, acuminatae, concavae, integrae, intus laeves, extrorfum pilofae, deciduae, tripollicares.

Pedunculi in apice ramulorum, et axillis foliorum fummorum folitarii, teretes, pilis raris confperfi, erecti, bipollicares.

\section{on Flores Mafculi ad folia fumma:}

cax. Spathae nullae. Amentum fubcylindricum, clavatum, carnofum, erectum, fpithameum, flofculis feffilibus, exiguis innumeris, teçum, caducum. Perianthium proprium minimum, bivalve, valvulis aequalibus, oblongis, obtufis, concavis, arete cohaerentibus, claufis, luteo fufcis.

COR. nulla. 
sTAM. Filamentum unicum breviffmum in fundo perianthii. Anthera ere\&ta, oblonga, fimplex, longitudine filamenti.

9. Flores Feminei in apice ramulorum.

CaL. Spathac bivalves, ovato-lanceolatae, compreffae, acuminatae, erestae, apice intlexae, molle, fpihameae, primum claufae, deinde deciduae, in apice pedunculi. Spadix? globofus, germinibus plurimis connatis tectus. Perianthium nullum.

$\left.\begin{array}{l}\text { cor. } \\ \text { stam. }\end{array}\right\}$ nulla.

PIST. Germina numerofa, obverfe conica, con: nata, receptaculo innata, apice convexiufcula, fingula fuperficie fubhexagona. Styli vix ulli, breviffmi fimplices, numero germinum, folitarii. Stigmata, puncta, prominula, marcefcentia, (in aliis varietatibus, bifidi; Thunberg).

PER. Bacca globofa, glabriufeula fuperficie hexagonis confcripta, pallide virens; maxima dodrantalis; pulpa farinacea, alba, fubfibrofa, maturitate fuccofa, flava; receptaculo clavato, carnofo, longitudinaliter fibrofo, palmari, adnata.

sEm. (in hac varietate). Rudimenta fterilia, minuta, oblongiufcula, emarcida, fufca, apice pilo decies longiore coronata, pulpae immerfa.

Varietates praecipuae huius arboris duae funt

a) Fructu apyreno; haec iterum in quinque ordines difpefcitur qu rum nomina lingua. taheitenfium vernacula funt fequentia: 
a) Uru, fructu apyreno globofo, laevi, mutico, vulgatiffinae, quam modo adumbravimus, varietati proprius.

b) Maira fruetu apyreno ovali, mutico, foliis profundius diffectis.

c) Patea, fructu apyreno, oblongo fcabro, quafi fquamofo.

d) Tatarsa, fructu apyreno, ovali, germinibus verrucofo mamillaribus fylo perfiftente muricatis; his accedit

e) Soccus lanofus Rumph. herb. amboin. I. tab. 32. fructu apyreno muricato, intus lanato-fibrofo.

B) Fruitu feminifero, cuius defcriptionem dederunt Rumphius et Sonnerat. Haec oim in Taheiti infula cum praecedente reperiebatur, fed progrefiu temporis negledta periit, quum apyrenae varietatis ad rem cibariam praeftantior fit ufus. Semina magnitudine fere caftaneas exaequant, oblonga, fubangulofa, utrinque in acumen producta, tùnicis propriis, brunnea et alba, corticata, fingula interftincta membranulis five tunicis pluribus (e germinum abortu) et carne minus abundante fuccofa. Haecce femina in primis Ce ebae infulae hominibus pro alimento praecipuo inferviunt, qui eadem cinere fervido tofta, vel in aqua cocta, vorant.

Apyrena artocarpi varietas conjunctim cum feminifera adhuc in marianis infulis reperitur; in novis porro Hebridibus ac in anicorum archipela- 


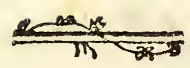

go, licet rarior, occurrit; copiofiffima autem omnium in focietatis et marchionis mendozae infulis, atque fatis abunde in Sandvigis nonnu is coitur. Vidi etiam feme artocarpi firpem juniorem in arboreto quodam novae Caledoniae, ubi inter rariffimas procul dubio recenferi debet.

Fruetus hicce apyrenus perfeete maturus, pu'pofus, dulcefcens, facile putrefcit, atque tum alvum fertur nimis laxare; immaturus vero farinaceus eft, et in fornace fubterranea, vel etiam fuper igne toftus, faluberrimum et gratiffimum nutrimentum praebet, fapore panis triticei non adeo diffinile, tametfi cum radicibus helia thi tuberofi five etiam fola. ni tuberofi quandam fimi itudinem habeat. Octo con. tinuis menfibus taheitenfes et adiacentium infularum marchionis incolae hocce inprimis cibo vefcuntur, neque per reliquos quatuor menfes, a Septembre in finem Decembris, fub ipfo inflorefcentiae et groffificationis tempore eodem prorfus carent, cum oco recentis fructus maffam pu'pae, fermentatione acidulatam, in panis fpeciem coquere probe norint, eamque in deliciis habeant. Liber arboris ad rem veftiariam pari modo, quo mori papyriferae liber, adhibetur; lignum pro cymbis, domibusque exftruendis; amenta mafcula pro fomite igniario; folia pro cibis involvendis manibusque abftergendis inferviunt. Succus lactefcens glutinofus coquendo infpiffatur, et in vifcum avibus capiendis idoneum convertitur; idem admiftum aliis ingredientibus gluten præbet, quod hydriarum fiffuris illini folet. Trium arborum annona ad alendum unum hominem fufficit. 
2. MVSA PARADISIACA. Linn.

M.(Paradifaca) fpadice nutante, floribus mafculis perliftentibus. M. S.V. p. $9<2$. n. $\mathbf{I}$.

M. (Sapientum) fpadice nutante, floribus mafculis deciduis $M, S, V \cdot$ p $902, \mathrm{n}, 2$.

Planta culta per totius orbis regiones calidas, in america ante hifpanorum adventum ignota, e guinea ad americae infulas aequinoctiales primum allata, in oceanum pacificum una cum hominibus ex orientali ndia migraffe videtur, ibidem enim in omnibus infulis, praeter demerfas et defertas, paffm colitur, et in varietates praefertim in archipelagis amicorum et focietatis numerofas degeneravit. Propagatur e radice et fto onibus, foveae immiffis, cum cinere herbisque concrematis, quibus ca cis e conchis interdum pauxil um adjici folet, ut fructus cito progerminent, hae praecociores varietates menfe fexto, immo quarto nonnunquam fructus proferunt, reliquae racemo nonnifi poft decimum octavun menfem onuftae cernuntur. FruCtificatione peracta, tota ftirps, excepta tamen radice novos agente furculos, emoritur.

Fructus, prout diverfa eft varietatum indo'es, a'ii crudi alii nonnifi tofti five affati comeduntur; horum priores hortorum taheitenfium praccipuum ornamentum conftituunt; pofteriores vero, utpote frigori magis affuefacti, in montuofis infu arum traetibus, locos nemoribus undiquaque claufos occupant. In moluccano archipe ago, pu'pam tofram horum fructuem mafticando in pu tem reducunt matres, quam infantibus etiam nolentibus in 
os ingerunt, eosque ut offam deglutiant variis artibus cogunt. Cibus eft facilis digeftionis, iis qui e longinquo itinere maritimo adpel unt maxime faJutaris et delicatus; mihi tamen, propter naufeofam glutinofamque du cedinem femper iniucundus. Vifcida haecce qualitas videtur ftomacho debiliori infenfa, conftipat a!vum, flatusque gignit. Rumphius etiam maturos crudosque mufaefructus, cum facile putrefcant, indyfenteria epidemica, malignitatem humorum adaugere credidit. Idem indefeffus naturae obfervator, in moiuccano archipe ago fedecim mufae varietates enumerat, quarum $\mathrm{p}$ urimae etiam in aufrafiae infulis reperiuntur: eas vero verbis exprimere, vel differentiam fpecificam veram qua Mufam paradifiacam a Mufa fapientum dignofcere liceret, me nondum reperire potuiffe, lubenter fateor. Figuras enimEhretianas a Rheedianis (Trew. t. 21. 22. 23 et Hort. Malab. p. I. t. 12. 13. 4). nihil difcrepare quis non videt, licet $b$. Linnaeus illas Mufae fapientum, has vero paradifiacae tribuerit?

I. Mufa corniculata, (Pifang Tando) cornu bovis figura et magnitudine fruktuum aemulat; variat fructibus mollibus flauis, quos femineos vocant, et maiculis dictis, duris, viridibus, longioribus, aufteris, ut nonnifi tofti aut coeti menfae apponi queant. Singula bacca faepe duodecim pollices longitudine exaequat, brachii fere craffitiem adtingit; quare racemus fuffulciri lolet, ne pondere fuo abrumpatur.

1I. Mu/a ex/uica (Pifang Gabba Gabba) parum a praecedente differt, nifi fructu tenuiore, ex albido flavefcente, fubftantia ficciffima, auftera, donec fub cineribus fervidis torreatur. 
III. $M u / a$ ietragona (Pifang Cro) frustus gea rit fithameos, angulofos, plerumque tetragonos, extus virentes, intus albos, acidulos, duriufculos.

IV. Mufa asicularis (Pifang Dfiernang). FruEus palmares, trigoni, acuminati, acumine longo filiformi, ftyli perfiftentis veftigio. Racemus feptem pedes nonnumquam longus eft, ducentos et quinquaginta fructus in feptemdecim verticillis non raro adnectens. Cortex, medullae rufefcenti et facchari inftar micanti, fortius quam in congeneribus adhaeret.

V. Mufa coriacea (Pifang Culit-Tabal). Cortex craffiffimus fruktus, recondit pulpam mollem, pallide rufam, pentagonam, ora interiore angufitfima. Haec quoque frixa aut tofta folet menfis apponi, licet etiam cruda eadem in cibum cedat modo bene matura fit. Ad hasce quinque varietates, quibus etiam decima adnumeranda, taheitenfum varietates fylvaticae et montanae, quas kebhi vocant, mihi fpectare videntur; harum maxima, maturitate extus et intus intenfe fulvo colore gaudet.

VI. Mufa menfaria (Pifang Medji). Hujus frußtus palmaris five fpithameus, teretiufculus, ftriis notatur quinque elevatioribus, obliteratis, inaequaliter difpofitis, vt fere trigonus appareat. Maturus e fulphureo colore fiavefcit, facillime decorticandus, puipa albida, frątura micante, fapida- dulci, ac fi aliquid aquae rofarum effet admiftum. Ad torrendum, nifi imm turus, non valet, fed crudus comeditur; facile putrefcit, cum et cito ad maturitatem perficiatur. Stipes altior quam in pluribus varietatibus; tolia furco maculata. Haec impri- 
Imprimis et proxima fequens, apud taheitenfes Meiya vocatur, vocabulo quod a voce malaica Medji parum ablonum videtur.

VII. Mufa regia, (Pifang Radja) gaudet fructu praecedenti affini, fed multo breviore, vix digiti longitudine, pollicem craffo, glabro, aequali, cortice tenuiore, fapore dulci et grato; quare a bataviae urbis incolis, maxime appetitur \& reliquis mufae varietatio bus palmam preripit, menfisque crudus apponitur.

VIII. Mufa purpurafens (Pirang Mera) forma fructuun cum M. regia convenit, colore differt; cum enim progerminent fructus externe purpureo fufci funt, croceo intermixto. Caro alba, acidula, edulis tamen fine praeparatione. Stipites, folia et racemi co. lore purpureo virenti infecti funt.

IX. Mufa pranctata (Pifang Salpicado)。 Fructus brevis, teretiufculus, flavus, minute nigro punctatus: cetera cum $M$. menfaria conveniunt.

X. Mura dorfata (Pifang Swangi). Frudus craf. fus, fex pollicaris, protuberantiis longitudinalibus inaequaliter angulofus lateribus irregularibus. Pulpa intenfe lutea feu rufa, duriufcula mucofa, acidula, fub. auftera; qua nec frixa, nec cruda vefcuntur homines, ad pultem tamen pro infantibus ufurpatur, et omnium vilifima, habetur. Stips reliquis altior.

XI. Mufa granulofa (Pifang Batu five Bidji); figura praecedentis, teres, tenuior, virens, pulpa imucofa, molli tamen et dulcefcente, repleta feminibus duris, nigricantibus inftar paconiae feminum. Stipes altus, per furculos adeo multiplicatur ut brevi tempore magnum fpatium occupet. Linnaeus hanc varietatem Mufae Troglodytarum adnumerar. 
XII. Mufa fatua (Pifang Alphuru) fructus gerit paruos, craffos, tereti compreffiufeulos, cinerafcentes, vifcofos, faporis fatui, toflos tamen bonos.

XIIT. Mufa coarctata (Pifang Bombor) eft fructu breuiflimo, ovi găllinacei magnitudine, glabro, tetragono, apice obtulo, crudo eduli.

XIV. Mufa papillnga, (Pifang Sufu). Minores quam M. menfaria fructus gerit, pollicem craflos, an: gulofos, apice papillaeformi, flavefcentes, pulpa dirufcula, acidula, vili, quae torreri potius debet, quam cruda comedi. Folia huius varietatis tenella, farina quafi confperfa funt, qua abrafa, color fufcus adparet, qualis et deglupta extima membrana in ftipite confpicitur.

XV. Mufa pumila (Pifang Kitfil) Stirps humilis, cum folis humanam altitudinem non excedit. Fructus rotundi, digiti longitudine, fed craffiores, extus lutei, glabri, corrice tenui fragili. Pulpa dura, acidula, tamen ut fertur, grata, et ficuum faporem fulcipiens fi fuerit in aqua cocta. Racemus licet humilis tamen ufque ad ducentos fructus non raro profert. Haec varietas gaudet folo pingui, terraque daedalaea, lapillis mixta, atque hortos montanos amat in fyluis abfconditos. Mufae reigae degenerem filiam putat Rumphius.

XVI. Mufa lunaris (Pifang Bulang-trang). Huius racemus, ftipes, folia flaua funt, fructusque albidi, ita ut noctu, lunae radiis illuminata, tota tirps fimilem colorem reflectat, unde nomen malaicum sacta eft. 
3. SPONDIAS DULCIS F.

S. petiolis teretibus fexjugis: foliolis ferratis, coftacisque $\mathbb{F}$.

Arbor procera, umbrofa, coma pulcra, late diffufa. Truncus crafitie, corpus humanum fuperat, erectus, ramolus, quinquaginta pedum altitudine, quotannis ante noum foliationem florens, menfe feptembri.

Rami diffuli, patentes, teretes, cortice brunnes, fcabro. Folia fparfa, conferta, petiolata, pinnata, fexjuga cum impari; foliola oblongo- lanceolata, acuminata, fubtiliffime ferrata glabra, patentia, contata neruo marginali, venis plurimis fimplicibus parallelis rectis, a rachi media in coftas ad angulum rectum excurrentibus, faturate viridia, palmaria. Petioli communes, teretes, laenes, patentes, pedales; proprii fuboppofiti comprefliufculi, femipollicares.

Pedunculus in apice ramelorum uninerfalis, terminalis, teres, laevis, erectiufculus, longitudine petioli communis. Racemus magnus compofitus. Pedunculi partiales alterni teretes, glabri, horizontales, fuperiores fenfim minores adfcendentes palmares; pedicelli vniflori, fparfi breuifimi. Flores parui, flavo - virentes.

CAL. Periantbium inferum, minimum, quinquepartitum lacinis aequalibus, acutis pallide viria dibus.

COR. Petala quinque lanceolata, patentiffima, calycis laciniis incerjecta, infera.

Neitarium? Annulus carnofus, torulofus, germen cingens, flauus,

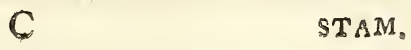


sTAm. Filamenta decem fubulata, petalis bre. uiora patentia. Antheras ouatae, erecto-incumbentes. coalita.

PIsT. Germina quinque minuta, globofa, bafi

Styli quinque cylindrici, bafi approximati, apice recurvi, longitudine ftaminum. Sigmata ob. tufa.

PER. Drupa oualis obtufa, magna, glaberrima, aurea, odore fub naufeofo foetida; putamine exteriom re tenuifimo, punctato, acri, dentes arrodente, amaricante, pulpa carnofa, fucculenta, dulci, acidulata, aromatica, fragrante. Nux in medio dura, lig. nola, ouata, fibrillis duris pungentibus undiquaque echinata, quinquelocularis, diflepimentis membra. naceis.

SEM. Nuclei folitanii, onati, comprefli, quamplurimum abortiui.

Haec foondiae fpecies per focietatis et Amicorum infulas colitur, inprimis in Taheiti frequentilfima. Eius fructus fue vere aurea poma in racenulis nutantibus proueniunt, et fapidifimis faluberrimisque juo re adnumerantur, ejusdem fere ac Bromeliae Ananae tructus faporis, fitim non folum facile tollunt fedanto que, fed etiam aegris, licet biliofis affectionibus et obfructionibus la'xorantibus, fine difcrimine conce. duntur; aluum leniter referantes, antifeptici, et inter. horaeos fructus digniflumi qui principem locum occus pent. Nomen taheitenfum $e-V i$. Determinent alii, an haec noftra fpecies cum fpondia Myrobalano Linnaei, M. S. V. p. 428. n. 2. fiue Celeberr. Jacquini fpondia Mombin conjungenda fit, nec ne. Si rectius fegre. 


\section{$e^{-25}$}

gavi, Linnaeanae fpecies novis differentiis fpecificis denandae funt.

4. CITRUS aURANTIUn. Linn.

C. petiolis alatis, folis acuminatis. $M$. S. Y. p. 697.n. 20

Aurantia mala in novis Hebridibus reperini andor erat Petrus Fernandez de Quiros, primus harum infularum inventor, gui eadem terrae Manicolae, five Mallicollo tribuit. In hortis harum regionum littori vicinis tamen thanc arborem nufquan vidunus, neque forfan teltimonio natarchi hifpani fidem adhibuiffemus, nifi tandem in extrema huits archipelagi verfus autrum porrecta Tanna infula, fondus aliquot inmaturos incolae femel venum obtuliffent, quos pro veris aurantis agnouinus Nen igitur dubitandum eft, quin haecce hefperidum poma $a b$ indigenis culta, rei cibariae harum infularum adnumeranda venianto

\section{CrTRUS DECURANA. Linn.}

C. petiolis alatis: follis obtufis emargio nacis M.S. D. p. 69\%. n. 3 .

Frequentifina eft in amicorum infulis arbor procera, unbrofa, pulche comata, Howbus fragrantinimis, fructibus maximis fapidntimis fuperbiens, qui belgice Pompelmoefen andiunt et inter congeneres omnium faluberrimi habentur. Hi fructus toti conftant paruis folliculis, facile et quidem fine diruptione pelliculae feparabilibus. Apud incolas infularum E. uwa fine Medioburgi, Namoka fue Rotterodami et Tongatabu fue Amftelodami, nomine Moliya difine guintur.

$$
\mathrm{C}_{2} \quad 6 . \mathrm{EJ}=
$$


6. eUgenia MalACCENSis, Linn.

E. foliis integerrimis, pedunculis ramofis lateralibus. M. S. V. p. 461 .

Haec arbo plurimis infulis oceani aufralis intra tropicos communis eft, et praefertion colitur in $\mathrm{Ta}$ heiti, congeriebus infularum Societatis, Marchionis, Sandvigii, nouarumque Hebridum. Fructus albicans eft rofeo tinctus, pyriformis, interdum pugni fere magnitudine, fed plerumyue multo minor, ex acidulo faccharatus, aqueus et fuccolus; falubris itaque et etiam aegros morbo inflammatorio decumbentes refrigeratione confortans. Corticem tritum et in lacte acido epotum Rheedius inter ancidyfenterica laudat. (Hort. Malab. I. p. 30.) Nucleus in centro drupae folirarius eft; perperam Parkinfonius (Journal p. 40) pericarpium feminibus farctum dixit. Arbor magna et procera, foliis maximis umbrofa, taheitenfibus Heiva vocatur. Dubito an praeter hancce fpeciem etiam Eugenia Jambos inter plantas infularum aufralio um ciuitate donanda fit.

7. FicUs ASPERA. F.

F. foliis oblique cordatis, finuato-dentan tis, vtrinque afperis: fructibus turbina. tis, calycis margine obfoleto adnato. F.

Arbor quatuor fue quinque orgyarum altitudine, foliofa, ramis articulatis.

Folia alterna fubpetiolata, ouato-cordata, acumi. nata, finuato-dentata, difco interiore angultiore, vtrinque alpera, pilola, patentia, fpithamea. Petioli breuifimi, alterni, fparf, teretes, fuperius fulco exarati, 
Receptacula axillaria, gemina, feffilia, turbina. to-globola, extus fericeo-tomentofa, alba, magnitudine Ficus Caricae Linnaei, carnofa, fuccofa, fapida. Calyx communis nullus; fed margo obfoletus integer vix bi feu tridentatus, receptaculum in ea regione cin. git, vbi magis dilatari incipit.

Colitur in hortis et arboretis Tannae infulae. Fructus dulces, grati, crudi comeduntur. Folia ju* niora cocta indigenis fapidum olus praebent.

Confer: Rbeed.Hort. Mal, p.inı. to 62.

8. Ficus granatum. F.

F. foliis ouatis integerrimis: pedunculis terminalibus, geminis horizontaliter divergentibus, fructibus calyculatis, glo. bofis. F。

Habitat cum praccedente in Tanna, fimiliter culta, propter fructum edulem, dulcefcentem, aquofum, fubinfipidum.

Arbo procera vmbrofa, caudice multangulo torofo. Rami omnes adfcendentes, longi, teretiufculi, fubarticulati, cinereofufci, inaequales, ramulis teretibus articulatis, apice tantum foliofis。

Folia conferta alterna, petiolata, ouata, integerrima, glabra, venis raris flauis, fupra intenfe viridia, inferne lucidiora, fpithamea et vltra, patentia. Petioli teretiufculi, glabri, patentes, longitudine quadrantis foliorum. Gemmae terminales arctiores fpiniformes, totae pilis badiis veftitae.

Pedunculi axillares folii fupremi et proximi, gemini, crafli, breuiflimi, teretes, horizontaliter diuergentes.

$\mathrm{C}_{3} \quad \mathbb{R e}$ 
Receptacula globofa, magnitudine Ficus Caricas Superant fubpubercentia, rolea, maculis flauis confperla. intus purpurea, pulpola mollia.

Calyx communis triphyllus, foliolis ouato fubrotundis paruis.

9. FICUS INUICA? Linn.

F. folis lanceolatis, integerrimis petio: latis, pedunculis aggregatis, ramis radicantibus, M. S.V P. 922 n. 7 .

Arbor in Tanna, nouarum Hebridum infula, mmbrofa, excella propter fructus parvulos er infipidos colebatur. H ex codem pundo fen cicaricula candicis plures aggregati proueniebant, ita vt totus truncus iisdem confitus efet. Defcriptionem buius foeciei ex meis Shedis deperdidi; an cun Ficu indica Linnei merito conjungenda fit, etiannum dubro. Eiusdem forte fpeciei eft Ficus in Tongatabu fponte nafcens; cuius fuctibus Cerafi minoris magnitudne incolae vefcebantur, et isdem nomen Matte impo. nebant, quod in o. Taheiti diuerfae prorfus lpecici, nempe $\mathbb{F}$. tinktoriae proprium. Cook. it. nouiff. Vol. 1. pag. 332.

IO. pandanus ódoratissma. Linn. M.S. V. p. 878 .

\section{Achrodactylis fpinofa Forft. Charat. gen. 75 .}

Radix. Caudices plures defcendentes, divergentes, altitudine femiorgyali fupra terram clevati, fimplices, teretes, glabri brachi crafitie, apice, vbi terran intrant, fibris aliquot praediti. 
Truncus arboreus bi feu triorgyalis, craffitie femoris, teres laeuis, annulis eleuatis approximatis no. tatus, erectus, interdum ramofus, cortice tenui cinereo, ligno fpongiofo. Rami fubdichotomi, ereło patentes, faepe dinaricati, teretes, e cafu foliorun annulati, apice foliofi.

Folia teminalia confertifima trificha vel tetrafticha, feffilia, enfata, longiffima, acuta, extus carinata, aculeis antrorfum verfis confertis in margine et carina vndique fpinofa, venis transuerfis rectis carinae perpendicularibus notata, glauca, tripedalia, bafi binos pollices lata.

Pedunculus terminalis, nutans, teres, glaber, bipedalis, Thyrfo decompofito, candido, pedunculis partialibus palmaribus, teretibus varie ramofis glabris, pedicellis pollicaribus, teretibus, erectopatentibus, naminibus confitis.

$o^{7}$. Flores mafculi. Bracteae alternae, lanceolatae, tenerae, erectae, margine ferratofpinofae, candidae, fefquipedales, florum thyrfos cole ligentes, loco fpathae.

$\left.\begin{array}{c}\text { cAt. } \\ \text { cor. }\end{array}\right\}$ nulla.

STAM. Filamenta plurima (duodecim ad triginta) pedicellis fparfim infidentia brevifima. Antberae oblongae, acutiufculae, erectae, filamentis multo lon. giores.

9 Flores feminei in diverfa arbore. Folia terminalia quatuor enfata, dorfo et margine ferrato fpinofa, pedalia, conniventia, fpatharum vices agunt. 
CAL. Spadix terminalis lubglobofus fructificatio. nibus numerofis tectus, viridis, fpathis non inclufus. Perianthium nullum.

COR. nulla.

PIST. Germina numerofa, cuneiformia, apice convexa. interdum tuberculata, receptaculo conico five globolo inlidentia.

Styli? rudimenta aliquot breviffima, in apice cuiusvis germinis vel e centro prodeunta vel etram in quolibet tuberculo germinis, folitarie difperfa.

PER. Fructus fubglobofus, maximus compofitus. Druplae numerofac, cuneate, apice convexae, lateribus angulofae; farinaceae, monofpermae.

SEM. Solitarium, ovale, haeve, magnitudine suclei olivae, in centro cuiusvis drupae.

Varietates: a) fructibus tuberculatis difcretis. Hort. Mal p. ji. t. 6.

B) fructibus convexis apice difcretis, $H_{\text {。 }}$ M. p.jj. t. 7 .

๖) fructibus convexis, trifulcis connatis. H. M. p. ji.t. 5 .

d) fructibus convexis fpinofis umbilicatis congeltis. H. M. p.jj. t. 8 .

Arbor littorea, fabulofa amans, fponte crefcit in oris maritimis infularm fere omnim intra tropicos, etiam demerfarum; fructu et foliis Bromeliae quo. dammodo fimilitudinem prae fe fert; caudice fingulari, apice tantum frondofo, palmis affinitate jungitur eodem ac torte maiori jure quam Stratiotes et Vallifneria. Flores mafculi pollent odore fragrantifimo, 
fed dantur etian varictates inodorae. - Arabes et Zey. lonenfes propter hunc odorem Pandanos mafculas co. lunt; Indorum mulieres, praefertim infulas orientales in habitantium capillos polline antherarum odoratiflimo confpergunt; folia floralia autem et thyrfi ra. cemulos in ciftis inter veftes reponunt. Ternatenfes eosdem flores nondum ápertos cum carne et pifcibus oleris loco coqusunt. Bandanenfes folia vulneribus imponunt, in aufralis autem oceani infulis ftoreae inde fiunt. Fruetus in India ab Elephantibus vorantur; in o- Taheiti et circumjacentibus infulis a pueris exfugillari folent; fi Artocarpus defecerit, etiam adulti jisdem vefcuntur. Sunt colore extrorfum toti auran. tii, intus flavi, odorem gratifimum et aromaticum fragorum vel Bromeliae Ananae 'pargunt, fubftantiam pulpofo - farinaceam, faporis primum dulcefcentis deinde adfringentis aufteri: vires ftypticas is ineffe docuit Rheede in Hort Malab. Fructus taheio tenfibus 6.Vara; flores mafculi Hinanno.

\section{MORINDA CITRIFOLIA Linn.}

M. arborea, pedunculis folitariis。 $M . S_{\text {。 }}$ $V \cdot$ p. $21 \%$

Inter fructus edules infularum aufralis oceani fuc. cedanei locum occupant huius arbufculae baccae, quae Taheitenfibus Nono vocantur, et pro cibo vfurpantur deficiente artocarpi annona. Ex Cookii noviffi. mo itinere cognovimus hofce fructus, qui crudi viridi-flavelcentes, aquofi et infulfi funt, coctos, five in fornace fubterranea affatos, faporem gratum acquirere. Hace Morindae fpecies in hifce regionibus fpontanea eft, cum paffim et quidem in defertis etian infulis reperiatur Baccarum vires anodynas laudat Rumphius in Herb. amb. jij p. 159.

C 5

12. 50 . 
I2. SOLANUM AVICULARE. H.

S. caule inermi fruticofo, follis finuatopinnatifidis: corymbis terminalibus. F.

Huius baccae fulvae, pruni majoris mgnitudine, acidae, parum dulcefcentes fubraufeofae, ab incolis Novae $Z$ eelandiae avide vorantur, aviculis etiam gratiflimae neque nof tratibus omnino rejiciendae. Habitat fponte in Novae Zeelandiae dumetis ruderatisque.

Caulis fruticofus, ereftus inermis ramolus, femiorgyalis. Rami herbacei, laeves, fubteretes, craf= fitie fere digiti, breves.

Folia alterna, petiolata, finuato-pinnatifida, inferius acuminata, pedalia, lacinis lanceolatis oppofitis, trium parium cum impari, lacvibus integris, faturate viridibus, palmaribus. Petioli femiteretes, lasves, patentes, fparfi.

Corymbi terninales duo five tres, pauci-flori. Pedunculus vniverfalis teretiufculus erectus, palmaris; partiales fex fen feptem, fparfi unifiori, teretes, laeves, patentes, elevatione proportionali, pcdunculo univer. fali quaf per articulationem impofiti. Flores violacei, pollicares, Raminibus flavis.

CAL. Periantbium turbinatum quinquefidum, lax ciniis brevibus acutis.

COR. monopetala plicato-rotata, tubo brevifimo, laciniis quinque margine plica aurtis.

sTAm. Filamenta quinque corolla breviora. Ana. tberae in tubum conniventes.

Prst. Germen oblongum. Stylus longitudine ftaminum. Stigma breve bilabiatum. 


\section{$\frac{2-2 \pi}{3 \pi+3-3 x}$}

PER. Bacca ovalis, aurea, bilocularis.

SEM. plurima nidulantia.

13. ACHRAS DISSECTA F.

A. floribus confertis, corollis ofodecimfidis: foliis obovatis emarginato-retufis. $F$.

A. diffecta. M. S. V.p. 342, Linn. Stippl. pl. P. 2IO.

Manyl-kara. Rheed. Hort. Mal. part jjo. p. 53. t. $25^{\circ}$

Advena in hortis Malabarorum colitur nomine Manylkara, five Karae manilenfis, cum ex infulis philippinis allatam adfeverent. Fructus huius arboris eft pomum, forma et magnitudine olivae, oblongum, viridinitens, vifcido et lacteo fucco refertum, matusius purpureum, intus rufum, fucculentum, carne acido dulci, femen unum alterumve continens (reliquis loculamentis abortientibus), nucleo albo amariufculo. Hi fructus ibidem inter bellaria comeduntur. Folia cum curcumae radice et zinziberis foliss cocta et contufa ad cataplafma contra tumores adhibentur, Brachmanis Manil - gale ( $\mathrm{fed}$ in tabula aenea nomen adfcriptum Vinvalli), Lufitanis Fruita $M a$ milha, Belgis Loe beffen five cbineefche pruynen vocantur; quod etiam apud Sinas crefcant. Arborem proceram, caudice craffo, ranis longe lateque comatam dixit Rheede. Mihi Cemel vifa eft in Tongatabu infula, menfe Septembri florens; fructus autem tune temporis nullos perficiebat. E fpecimine ficco, quod pater optimus nobilifimo D. Baeck, Regis Sueciae Archiatro cum plurimis aliis dono miferat, Linnaeus, filius, defcriptionem, quamvis imperfectan collegit, fimul 
funul et nomen refcivit, quod huic plantae impolueram; inventorem invide fedulo reticuit.

Caulis arboreus, erectus, cortice cinereo rufe cente, tuberculato teçus. Rami lignofi, horizontaliadlcendentes, teretes, tuberculati, cubitales (in noftro fpecimine). Ramuli erecto-adfcendentes, fecundi, teretes, tuberculati, apice foliofi, fpithamei,

Folia fparfa, conferta, petiolata, oblongo - obovata, apice fubemarginata, integetrima, erecto - patentia, glabra, coriacea, fupra dilucide viridia, fub. tus pallidiora, bipollicaria. Petioli teretes, tenucs, erecto- patentes laeves, fere pollicares.

Pedunculi uniflori conferti, vadique e ramulis in. ter folia prodeuntes, filiformes, patentes, faepe horizontaliter-dependentes, numerofi, longitudine petiolorum. Flores albidi diametro femipollicari.

CAL, Periantbium hexaphyllum, patens; foliolis ovatis obtufis, tribus exterioribus viridibus, interioribus tenerioribus albis.

cor. monopetala, oftodecimfida. Laciniae fex majores lineares erectae, lateribus involutae, calycc longiores, ftamina ante eruptionem foventes; duodecim dimidio minores, per paria inter majores pofitae, lineares, acuminatas, extrorfum revolutae. Nectaria e foliolis fex ovatis acuminatis inter lacinias majores corollae ad bafin minorum pofitis, erectis.

STaM. Filamenta fex, fubulata, erecta, ante apicen parum infexa, longitudine calycis. Antberae incumbentes, lineares, acutae, bafi bipartitae.

PIST. Germen fuperum, exiguum, mulcilocula. re. Stylus corollalongior, filiformis, parum curva. tus. Stigma capitatum.

PER。 
PER. \& non vidi, fed baccan five pomum e ger.

SEM. $\left\{\begin{array}{l}\text { mine fieri ut in congen } \\ \text { tione Rheedii conftat. }\end{array}\right.$

Partes herbaceac huius arboris omnes lactefcunt. Inter fpontaneas harum infularum retuli, inlcius, an fructus ab incolis pro cibo ufurpentur.

\section{CRataeva religiosa. F.}

\section{C. inermis, foliolis aequalibus $\mathrm{F}$.}

Reperitur ad Coemeteria infularum o. Talseiti et Societatis, culta et deorum numini facra. Fructus profert minus fapidos, edules tamen, quales Crataeva Tapia Linnaei, tefte Rheedio; huic fpeciei etiam nimis affinis eft; an cum eadem vltro conjungenda fit, dijudicent yui Tapiam obfervarunt. Noftra apud taheitenfes $\varepsilon-P u r a \cdot a u$, five $P$ usrataruru vocatur.

Truncus arboreus, mediocris altitudinis, erectus, ramofus. Rami patentes, teretes, adfcendentes, lignofi, cortice oliuaceo, punctis elevatis albidis afperfo.

Folia fparfa, petiolata, ternata: foliola ovatolanceolata, acuta, acuminata, integerrima, glabra, tenera nervis venisque plurimis reticulata, fithao mea; lateralia parum minora margine antico anguftio. re (fed non breviore) horizontaliter patentia. Petioli communes fparfi, patentes femiteretes, laeves, palo mares; partiales breviffimi.

Cyma terminalis fubcorymbofa, femipalınaris; interdum flores folitarii ex axillis foliorum fummorum. Pedunculi vniflori teretes, laeves, laxi, palo mares, patentes, bafi craffufenli: Flores lesquiunciao les, sxalbido virentes, ftaminibus rubicundis.

CALI。 
CAc. Periantbium margine inflexo receptaculum bafi umbilicans quadrifidum, laciniis lineari-oblongis, acutis, longitudinaliter rugofis.

Cor. Petala quatuor (dento colore folia perfecte mentiuntur) erecta, ovato lanceolata, integerima rachi dorfali venisque reticulata, laxa, tenera, candida, bipollicaria; unguibus calyce vix brevioribus, virentibus intus canaliculatis, extus convexis.

stam. Filamesta fedecim, filiformia receptaculo inferta (nec gynandra) erecto patentia, petalis paullo longiora. Antberae oblongae, verfatiles, inclinatae, e flavo rubicundae.

PER. Germen oblongum, pedicello longitudine ftaminum filiformi clevatum. Stylus nullus. Stigma felinle, plenum, obtufum.

FER. Bacca? oblonga, bivalvis? unilocularis, pedicello ad palmarem longitudinem elongato inficiens.

SEM. oblongo - ovata, parieti valvularum af a fixa. -

I5. coriaria sarmentosa. F.

C. procumbens diffufa, follis cordato. ovatis acuminatis integerrimis quinquenerviis, fubpeciolatis: racemis axillaribus elongatis nutantibus. $F$.

Habitat fponte in fruticetis et dumetis Novae Zeea landiae. Barbari huins regionis incolae, inprimis ii, qui portum obfurum (Dulky bay) accolunt, baccatos fructus huius fruticis colligunt, et disdem vefcuntur. 


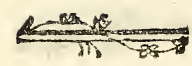

Caulis fruticolus, vix arborefcens, diffufus ramo. ffflumus, farmentis elongatis decumbentibus, tetragonis, laevibus, virefcentibus, foliatis.

Folia oppofita fubcordato-ovata, fubpetiolata, inferiora fubfeflilia, omnia integra acuminata acuta, horizontalia, laevia, quinque-nervia, palmaria. $\mathrm{Pe}$ tioli teretiufculi brevifimi.

Pedunculi axillares foliorum fuperiorum, folitan rii, reclinati, fpithamei; racemus fumplicifimus lon. gus cylindracets nutans, pedicellis unifloris fparfis, teretibus, filiformibus, laevibus, erectis, lemipollicarim bus, bracteatis.

Braçteae breviffmae minimae ad bafin pedicello. rum extrorfum pofitae folitariae. Flores minuti virides, hermaphroditi.

CaL. Periantbium inferum, perfiftens breve, quinquepartitum, foliolis fubrotundis concavis adpreffis.

COR. Petala quinque viridia, ovata, patentia, calycem longitudine aequantia.

stam. Filamenta decem capillaria corolla longio. ra. Antberac ovato-erectae, longitudine calycis.

PIST. Germina quinque depreffo- coalita Siyli quinque filiformes acuti, patentes reflexi decidui, longitudine ftaminum. Stigmata fimplicia.

ZER. Bacca globolo - depreffa, quinquepartitz atro-purpurea, e petalis carnofis, conniventibus, femina tegentibus.

sEM. quinque reniformia, ftriata, glabra. 
Nobis haecce fpecies femper floribus hermaphro. ditis vifa elt, nufquan vero mafculi aut feminei fe: orlim reperiebantur.

\section{II. \\ N U.C C E S.}

\section{6. cocos NUCIFERA Linn.}

C. inermis, frondibus pinnatis: foliolis replicatis enfiformibus. M. S. $V . p_{0}$ $985 . \mathrm{n} \mathrm{I}$.

Infulae oceani auftralis quae intra tropicos fitae funt, fere omnes hanc utilifimam palmam ferunt, humiles etiam illae, quae vix fuperficiem fali fupereminent et lithophytorum aedificis fuperftructae lunt, ut plurimum harum arborum altiflinarum coma condecorantur. Spontaneis igitur harm regionum vegeta. bilibus casden adnumerare non dubitamus, licet etiam cultae ibidem dentur varietates, quas ut exempla in novis hebridibus docent, hominum cura nobilitavit, et praefertim ad rem cibariam meliores reddidit. Hasce varietates, notis exterioribus tamen minus ab invicem dignofcendas, difertis verbis enarravit Clariffmus Rumphins, qui fimul de ufu harum arborun multifario fufus differuit. Heic loci meminifle fat erit, nucibus Cocos triplex ineffe alimentum, nempe junioribus lympham faccharatam, maturo fructu in materiam fpongiofam cotyledonis novi furculi coagulabilem; in adultioribus autem nucleum candidifimum dulcifimum fragrantem, amygdalos longe praecellentem, primum mollem gelatinofum lacteum. deinde perfecta maturitate duriufculum, oleofum, ultimo deinceps loco ipfum huius nuclei ole. 


\section{$\frac{2020^{\circ}}{m+830}$}

oleum, blandum, purum, dulce, variis ferculis admifcendum, nec non ad ufus medicos cunctos idoneum, ubi oleum amygdalorum adhiberi folet. Inco. lae praeprimis infulae Taheiti et adjacentium infula. rum Societatis hocce oleum imbutum odoribus variis, guorum pretiofifimus, et fragrantifimus e ligno Santali extrahitur, pro unguento caefariei five etiam totius corporis ufurpant, eodemque omnia membra crebro perfricare folent. I pfum nucis putamen, duriffimum in adulta, in juniore tamen ante nuclei formationem molle, inftar caulium braflicae edule eft. Omnium porro palmarum cor five caput ut vocant, ad trunci fummitatem, pedes binos vel tres longun, rudimenta frondium et fructificationum anni infequentis laminis tenuiffmis convolutis fovens, itaque pro gemma vere habendum, optimum alimentum praebet, nuci coryli avellanae et pedunculo braflicae cauliflorae palmam eripiens; fed hoc fine arboris deftructione obtineri non poteft. De vino palmarum quod colligitur e fpadicis nedum erupti vulnere, cum id hominibus anfraliae haud innotuerit, ut et de multiplici materiei, frondium, foliolorum, fibrarum, nucumque ad rem familiarem et mechanican ufu quaecunque differi poffent, utpote citra noftrum propofitum praetermittenda funt. Taheitenfibus Ari, nuces juniores Nia.

\section{CORYPHA VMBRACVLIFERA Linn.}

\section{C. frondibus pinnato-palmatis, plicatis} filoque interjętis, ftipitibus ciliato - fpinofis. M.S. V. p. 984 .

Huius folium femel vidi in Waitahu, five Chriftinae infula archipelagi marchionis mendozae; palmam ipfam deinde, fed minus frequentem in Tonga- 
tabu, amicorum infula reperit Cookius (vide Itin. no: viff. Vol. 1. p. 332. ) incolis Biu dictam, qui nuces eius globolas parvulas inter edulia habent.

18. INOCARPVS EDVLIS. F. $M S . P . \mathrm{p} \cdot 408$.

'Taheitenfes huius arboris fructum Rattá vocant, ipfam arborem $H i$ appellant, quod a voce If apud Papuanos in Nova Gumea ufitata non admodum differt; nuces $E$ - ifi, quas Cookius in noviffimo itinere Tom. 1. p. 393. commemorat, ad Inocarpum quoque procul dubioreferri debent. Earum nucleus reniformis compreffus, pollicaris circiter diametri, affatus et decorticatus ab infularum Societatis, Anicorum, marchionis, novarum Hebridum, novae Guineat et moluccarum incolis comeditur. Noltrates hanc nucem caltanearum loco habebant; fapor ramen minus gratus eft, licet dulcefcens; fubftantia durior, minus farino:a, ventriculo debiliori non conducit. Vires plantae et praefertim corticis adltringentes, alvum obftipant, et dyfenteriam fiftunt; quare etiam ad hunc fcopum in nofocomio amboinenfi decoctum aquofum corticis crebro adhibetur, tefte Kumphio; licet hoc medicamine aegrorum vita periclitari potius gu $3 \mathrm{~m}$ fanitas reltaurari videatur. Papuani fucco exprifio glutinofo, refinofo telorum apices obliniunt, hoc: aum tem gluten exficcatione nigrum colorem induit. Forte et refinofum illud, quo fagittas Mallicollenfium obductas vidimus et quod illorum aftutia pro veneno nobis vendirabat, ex Inocarpi fucco pariter praeparatum erat. Nomen arburis apud Mallicollenfes Nias audit, apud infulae Tannae indigenas immer. Inocarpum arboribus cultis in hisce regionibus vix ad. numerarem, etfi in focietatis infulis forte colitur. 
Arbor excelfa, crafitie corporis humani, cortice fufco rimofo. Rami lignofi tereres, patentes, varie divili, fulci, rimofi.

Folia alterna fubdifticha, petiolata, ovato-oblonga, vix cordata, obtufa, retufaque, rarius acuta, integerrima laevia, patentia, venis plutimis reticulata, Epithamea, (juniorum arhorum pedalia). Petioli teretiufculi patentes, laeves, transverfin ftriati, femipollicares.

Yedunculi univerfíes axillares, fubfolitarii, tereres, patentes pube nigra te $\mathrm{Ri}$, palmares. Racemus filifornis fimplicifimas. Pedicelli breviffuni, fparfi, conferti. Flores obfenre albidi, vix femunciales. NB. Racemus in Linn. Suppl, pl. p. 239. perperam Spica vocatur.

c Ax. Periantbizin monophyllim bifidun, laciniis fubaequalibus, rotundatis, pube nigra veftitis.

cor. monopetala tubulofa. Tubus cylindricus longitudine calycis. Limbus quinque vel fexpartitus calyce longior, laciniis linearibus undulatis patentio reflexis.

STAM. Filamenta decem vel duodecim brevifima, tubo duplici ferie inferta, ordine fuperiore in ip a fauce, cum inferiore alternante. Antberae parvae, ovatae, erectae.

Pist. Germen oblongum villofum. Stylus nullus. Stigma? punctum exiguum excavatum.

'PER. Drupa magna, reniformis vel ovata, comprefra viridis, monolperma, pulpa carnofa tenuis

D) $\approx$

SEM, 
SEM. Nux folitaria, ovata, conftans e fibris lig. nofis, craflioribus intertextis: nucleo ovali, com. preffo, albo.

OBS. Pili in germine, an fylorum vices agunt?

\section{TERMINALIA CATAPPA. Linn.}

T. Foliis obovatis, fubcus tomentofis. $M$. S. $V \cdot$ p. gro.

In hortis infulae Tannae fomel hanc arborem vidimus, menfe Augufto five fub finem brumae foliis orbam, fructu maturo in ramulis haerente. Arbor erat vafta, et excelfa. Drupa tripolicaris, ovata, fulcata, nucleo oblongo, avellanae nucis fapore, quare etiam in Banda et Batavia inter obfonia cum aliis fructibus menfae apponitur, ab Europaeis enim pluris exiftimatur, quam $a b$ indigenis, quippe qui vilipendunt quicquid ventrem non adeo implet. Apti funt hi nuclei, qui amygdalorum loco adhibeantur, fed oleo tam copiofo non pollent. Plantari folent huius generis arbores circa aedes in areis amplis, ubi fedilia eollocantur, propter denfam lateque extenfam quam praebent umbram. Materies exfruendis navigiis idonea, levis enim eft et in aqua marina per multos annos perdurat. Cortex et folia nigrum pigmen. tum praebent, quo dentes Indorum inficiuntur, nec non atramentum Indicum inde componitur. Hanc arborem ter fingulis annis maturos fructus perferre auctor eft Rheede.

20. TERMINALIA GLABRATA F.

\section{T. foliis obovatis, utriusque glabris. $F$.}

Differt a Terminalia Catappa, foliis in pagina inferiore pube deftitutis, duplo minoribus, nuce tri- 
plo minori glabra, ovali, minime fulcata, neque marginata, fed apice acuto, compreffo et membranaceo quafi appendiculata: differentias effentiales curatior inflitura comparatio forte fuppeditaret; fed $\mathrm{T}$. Catappan, ut fupra monui, nonnifi foliorum et florefcentiae ornatu fpoliatam vidimus.

Haec noftra fpecies autem colitur ad tuguria et coemeteria infularum focietatis; in amicorum infulis mihi fponte provenire videbatur. Taheitenfium lin. gua vocatur Alubiri, five etiam $e$ - Tara - iri et $e$ - Ta ra heiriri, diisque facra habetur. Materies pro exAruendis cymbis, tympanis, fcamnisque ufurpatur. Nuclei edules funt et inftar amygdalarum gratum faporem habent, Arbor excelfa, ramofa, diffufa, ramis fuboppofitis, teretibus, patentibus, laeviufculis, cortice cinereo rimolo.

Folia terminalia, conferta, petiolata, ovata, ob. ovataque, obtufufcula, integerrima, patentia, gla. bra, laevia, Spithamea; petioli teretes, patentes, villo brevi rufefcente veltiti, vix unciales.

Pedunculi axillares foliorum fummorum, fim. plices, teretes, filiformes, erecti, apice deflexi, glabri, fpithamei Racemus fimpliciflimus, floribus fparfis albidis: mafculis in parte fuprema pedicellatis; hermaphroditis in parte infima fimillimis fed revera feffilibus, cum ipfum germen inferum vices pedicelli agat, reliquas partes fructificationis elevantis.

o?. Flores Mafculi.

CAL. Perianthium campanulatum, quinquefidum laciniis ovatis, acutis, aequalibus, erectis.

cor, nulla.
D 3
Necta. 
Nifiarium urceolatum in fundo calycis, conftans corpufculis quinque minutis brevibus, duriufulis, pilis crebris longioribus veftitis, calyce dinnidio bre. vipribus.

sтam. Filamenta decem fubulata, erecto patentia, fundo calycis inferta, horum quinque exteriora longitudine calycis, interiora minora. Antberae ovatae, didymae, ereckae.

ఫ̧. Flores Hermapliroditi numerofi ufque ad disnis dium racemum.

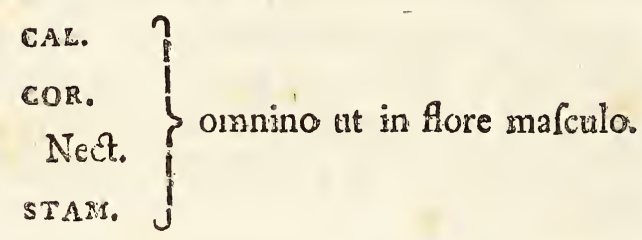

PIST. Germen inferum, ferile, ovato-oblongum, bati incraftatum. Stylus fuperus, e fundo calycis, villo necłarii cinctus, filiformis, erectus, longitudine Ataminum. Stigma limplex.

PER. Drupa ovalis, fefflilis, acuminata, apice marcefcente, compreffa, viridis, monofperma.

sEM. Nux offea, ovalis, sucleo folitario, ob longo, albo.

21. MABA MATOR. F.

M. - - -

Huius fractus cum illo Mabae ellipticae noftrae in omnibus convenit, practerquam quod triplo maior fit, bipollicaris fcilicet, in loculamentis fuvens nucleos triguetros, tenaces et infipidos, tamen inter edulia ab incolis ufurpatos. Incolae infularum Ton- 
gatabu, Namoka, E-uwa, Hapa-i, ct ceterarum quae ad archipelagum amicorum pertinent, hane arborem tefte Cookio in novif. itin. tom. 1. p. 393. circa tuguria plantare folent. Nobis non nifi drupa, ab incolis iisdem venum afportata innotuit, cui no. men Maba impofuerunt.

\section{Stercvlia BALANGHAS. Linn.}

S. foliis ovatis integerrimis petiolatis, floribus paniculatis $M . S$. V.p. 866 . n. 1 .

In Tanna infula, e novarum Hebridum congerie, hanc arborem hinc inde in nemoribus reperi, exeunte hyeme florum paniculas et foliorum novam pro. geniem e gemmis exferentem, fructibus praeteriti anni adhuc in ramulis perfiftentibus Cultis forte adnumerari debet. cum eius nuclei, iuxta Rumphii teOtimonium non folum affati eduies fint, et ab Amboinenfibus in hunc ufum adhibeantur; fed et capfulao combuftae pigmentum Caljomba dictum praebeant, cuius frequens eft ufus apud hosce populos.

\section{Stercvlta foetida. Linn.}

\section{S. foliis digitatis. M.S. V. p. 866.}

Huius cum praecedente eadem eft ratio, et ufus idem. Semel vifa eft, et quidem culta, in Tanna infula.

\section{III. \\ R A D I C E S。}

24. CONVOLVVLvs CHRYSORRHIZvs. Solandr.

$\mathrm{C}_{0}-\ldots$

D.

Con: 
Convolvuli fpecies radice magna, tuberofa, farinacea, intenfe fulva, naufeofo-dulcis, in oceani pacifici, infulis intra tropicos fitis non folum, fed etiam extra tropicum in Pafchatis infula (Oftereiland) et in Novae Zeelandiae regionibus borealioribus paffim inter plantas cultas reperitur. Hanc pro varietate Convolvuli Batatae habui, b. Solander autem qui etiam herbam et florefcentian vidit, ad novam fpeciem retulit, cui nomen Convolvuli chryforrhizi impofuit, tefte Parkinfonio (Journal. p. 37\%). Quod fi cum Rumphio credimus Convolvulum Batatam Linnaei ante adventum Hifpanorum ex America meridionali, in Philippinis et Moluccanis infulis prorfus ignotum incognitumque fuife; inde novo argumento Illuftris Solandri fententiam confirmari intelligimus. C. Batatas enim apud incolas infularum Amboina, Banda, Ternate, Baly, cognomine adiecto Caftcla diftinguitur, quo eundem ab bifpanis (caftilianis) acceptum indigitant. Taheitenfibus autem et reliquis oceani au= ftralis gentibus illa fpecies, quae harum infularum propria videtur, Umara audit, vel cum adfpiratione $G u$ marra aut Gumalla.

25. DIOSCOREA ALATA. Linn.

- D. foliis cordatis (oppofitis) caule alato bulbifero. M. S. $V$. p. 888. n.

Ubi vulgare, digitatum, anguinum, anniverfarium, ovale. Rumph.amboin. V. t. 120. I 2 I. 122. 123. 125.

Synonyma omnia heic enumerata utique referri debent ad D. alatam, cui nomen fativae meliori iure competit, quam illae fpeciei foliis alternis, quam b. Linneus, nefcio qua inductus ratione fativam deno- 
minavit. Haec enim D. alata Linnei tam in India orientali, quam occidentali, nec non in Africa aequinoctiali et etiam paffim in oceani auftralis infulis intra Zonam torridam, immo usque ad Novam Zee. landiam, ab incolis colitur ob fapidiffimas faluberrimasque radices, quae toftae aut fimpliciter coctae panis loco adhiberi poffunt.

Ubi vulgare Rumphii (t. I20.) quod Linneus inter fynonyma D. oppofitifoliae retulit, certo certius ad D. alatam pertinet, et enim folia cordata et caulem alatum et bulbos in caule ( $\mathrm{p} .347$.) gerit.

Radix faepe tripedalis eft, et triginta librarum ponderis, craffitie femoris, cortice nigro, carne alba feu purpurafcente, vilcida, poft coctionem farinacea. Succus radicum recens acris eft, et in cute pruritum excitat. Nucleus Cocos rafpatus cum Mufae pulpa et Diofcoreae radice commixtus, frixusque in formam pultis, Taheitenfibus in deliciis habetur. Varietas radicibus fubdigitatis, Rumph. t. I2I. frequens occurrit in Amicorum infulis, ubi etiam anguinam iftam Rumph. t. 122. vidimus, et aliam, cuius radices minufculae pondus unius librae vix fuperabant, cortice cinereo-albido (Cook. it. noviff. 1. c.) . In omnibus hisce infulis malaico vocab lo Ufi five Ubi no. tifima eft.

26. ARUM ESCULENTUM. Linn.

A acaule, foliis peltatis ovatis integerrimis: bafi emarginatis. M. S. $V_{0}$ p. 827. n. 7 .

Indigenae infularum aufralium in huius radicis operofa cultura maynos labores fubeunt; gaudet enim folo inundato primis menfibus, deinde in ficco 
collocanda eft, ope folfae circa campos ductae. Radix magna, tuberola, nutrimentum commune horum hominum, acerrima eft, crudaque oris pruritum et excorsationem caufatur; in cinere autem fervido toAta, acrem hanc qualitatem anitrit, fitque blandior et fapida, gravat tamen ftomachum debiliorem, alvumque conftipat. Folia difci vel orbis loco, guo cibi imponendi funt, in India ufurpantur, funtque fuperne glauca et inftar ferici tomento imperceptibili molliflima. Javanice haec fpecies vocatur Tallas, taheitenfibus et novae Zeelandiae incolis Tallo five Tarro. Reperitur paffim in omnibus infulis oceani auftralis, intra tropicos, exceptis defertis et demerfis; colitur etiam in nouae Zeelandiae extremirate boreali. Kelady fativum Rumph. herb. amb, tom. V. p. 313. t. 109. ad hanc fpeciem potius quam ad A, Colocafiam pertinere videctur.

\section{ARUM MACRORHIZON Linn.}

A. acaule, foliis peltatis cordatis repandis: bafi bipartitis. M. S. V. p. 827 . n. 8 .

\section{Arum fativum Rumph amb. V. t. 106.}

Colitur paflim cum praecedente. Radicem feus potius ftipitem habet maximum, brachii craffitie et Iongitudine, quo elixo et a volatili acredine liberato indigenae vefcuntur. Folia maxima ampliffima, ustrinque nitida, glabra, laete virentia. Fructificatio a charactere generico aliquanto recedit, flofculis in fpadice omnibus et fingnlis hermaphroditis.

COR, nulla. 
stam. Filamenta nulla. Antberae fex, fpadici adnatae, didymae, fingulos ftylos cingunt.

rist, Germon fubrotundum. Stylus folitarius, brevis, craflulculus, apice deprefflus. Stigma, macula orbiculata in apice Atyli.

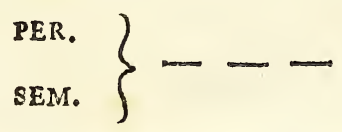

Taheitenfibus vocatur Apè; ceylanenfibus $\mathrm{Habc}_{\text {- }}$ $r a$; incolis infularum Amicorum et Sandvigrarum Kappe.

28. tacca PinNatipida. F. $M . S . \quad V_{0}$. $455^{\circ}$ n. I.

Tacca fativa, et fylvatica. Rumph.amb. tom. V. tab. II 2. II4.

Radix tuberofa, tuberibus pluribus congeltis, fibrilo las hinc inde emittentibus.

Folium radicale fubfolitarium, petiolatum, ternatum biternatumve, foliolis laciniato- pinnatifidis, act?. tis, laevibus, patentibus ad latera petiolorum fubdecurrentibus, dodrantalibus pedalibufve. Petiolus teres, fiftulofus, fulcatus, (in varietate domeftica laevis, maculis fordidis variegatus) bafi infuna fcapum vaginans, patens, laevis.

Scapus femiorgyalis, herbaceus, fiftulofus, verfus apicem lulcatus, erectus. Vmbella terminalis feffilis fimpliciffina. Inuolucrum circiter heptaphyllum, foliolis bipollicaribus, duobus exterioribus fefo filibus, pinnatifidis, caeteris fpatulatis laevibus, lamina fubrotunda, apice acumine brevifismo. Peduncu* 
li quatuor ad octo vfque, fere longitudine involucri, fimpliciffini, fubangulati vniffori, patentes. Fila octo feu duodecim longifima involucro pluries longiora patentia, exta umbellam dependentia, intorta, pedunculis interjecta, bractearum loco adfunt.

Gal. Perianthium fuperum, hexaphillum, perfiftens, foliolis ovatis, acutis, erecto - conniventibus receptaculo infertis, tribus interioribus latioribus.

Cor. Petala fex aequalia calyce tecta, eoque dimidio breuiora, fornicata, medio feu collo anguAtiora.

sTam. Filamenta duodecim breviffima feu vix ulla, petalorum cucullis, per paria inferta. Antherae oblongae, retrorfum arcuatae, unifulcae in medio dorfi parieti fornicis petalorum per paria affixae, et ita arcte approximatae ut binae unicam referant.

PIST. Germina tria conniventia? vel faltim unum trilobum exiguum, Styli tres brevifimi. Stigmata obcordata biloba.

PER. Bacca ficca, nigra, ovata, rugofa, obfolete angulata, calyce coronata, trilocularis polyfperma, diffepimentis exficcatis: immatura hexangularis, carnofa, diametro bipollicari.

SEM. plurima, ovata, compreffa, ftriata, brun: nea, pulpa exficcata cohaerentia.

Radix Taccae cruda inter amariffimas acerrimafque jure habetur, tametfi cultura hanc proprietatem aliquanto mitigavit. Rafura radicis crudae, aqua fubigitur, quae continuo abiecta et lotione reiterata, farina tandem in fundo vafis dejicitur candidiffima, amylo fumillima, iterum bis terve abluenda, donec in 
aqua nulla deguftari poflitit acrimonia. Farina ad folem exficcatur. Prima lixivia five infufa follicite abjiciuntur, cum e radice noxias, immo lethiferas adeo qualitates in fe fufceperint. n Taheiti adjacentibusque Societatis infulis ex hac facina placentam gelatino. fam praeparant, fapidam, et inftar Salep, quod ex Orchide Morione (nec non O. militari et mafcula) paratur, bene nutrientem. In Banda, moluccani archipelagi infula ubi panis e medulla Sagueri arboris factus non abundat, farinam Taccae in plagulis lapideis prius calefactis compingunt, pinfuntque placentam five panem quadratum ipfo Sagu meliorem. Vfus medicus huius radices apud eosdem homines viget, qui eandem emplaftri forma vulneribus profundis, telo vel tribulo inflictis imponunt. Sylveftris varietas Taccae, phalli fpeciem parafiticam e radice prodeuntem fuftinet, a Rumphio delineatam, nobis autem non vifam. Varietas fativa taheitenfibus $P i a$, fylveltris $\epsilon-V e$ dicitur.

\section{DRACONTIUM POLYPHYLLUM. Linn.}

D. fcapo breviffimo, petiolo radicato la. cero, foliolis tripartitis, laciniis pinnatifidis. M. S. $V_{0}$ p. 829. n.

Colitur in locis umbraticis nemorofis infularum Societatis; taheitenfibus Telpeb dictum; quod tamen nimis nomini Taccae filveftris conlonum efle videtur.

Radix acris, ficut omnes huius ordinis (piperitarum); ab incolis comeditur, deficiente artocarpi annona. An isdern quoque vires huius radicis medicae, quibus Japonenfes, telte Thunbergio (Fl. Jap. p. 234.) abutuntur, innotuerunt? Gravis quidem, fed vix injuriofa fufpicio, $f \mathfrak{i}$ ad milites iftarum infularum Errioy dictos, refpicimus, qui etiam recens enixos par- 
tus amicarum iugulant, vt barbarae legi fatisfaciant, de non lufcipiendis liberis.

30. DGIDGI, radix. (Jeejee)

\section{MAWHAHA, radix.}

Hae radices reperiuntur in amicorum infulis, atque cultura conveniunt cum Mula et Aro. Mawhaha fapore radicibus folani tuberofi fimilis effe dicitur. Mentionem harum primus injecit Cook in novifs, itin. Vol. I. p. 332. 393.

\section{DRACAENa terminalis, Linn.}

D. herbacea, caulefcens, foliis lanceolas tis. M. S. $V$. p. 334. n. 4.

Radix cylindrica, praemorfa, brevis, fibrillas raras emitit. Caulis trutefcenti - herbaceus, teres, eręus, é cicatricibus foliorum emortuorum quafi fqua matus, fere orgyalis, faepe ramofus, ramis erecto patentibus, adfiendentibusque, faepe etiam nullus vel breviffinus, apice foliofus.

Folia petiolata, terminalia, conferta, ovato- lan. ceolata, acuta, actminata, integerrima, laevia, multiplinervia erecta glabra, bi feu tripedalia; petioli pe. dales five bipedales pollicem craffi, erecti, canaliculati, equitanti-imbricati, caudicis apicem veftientes.

Pedunculus femiorgyalis teres, laevis, erectifculus, craflitie digiti. Racemus decompofitus, fpicatus, fo. liatus. Pedunculus vniverfalis erecto- patens teres, laevis, fulcatus; partiales alterni, teretes, laeves, fulca«i, patentiffimi, pedales et ultra, partialiores cjusdem fitus et figurae fupremi fenfim minores, omnes [picati. Flores \{parfi, feffiles, confertiufculi, albi aut in varietate $\beta$ purpurei, femipollicares, Stipulae? foliis 
Crmilimae, oblongo lanceolatae, fefiles, intcgerrimae extús ad bafin pedunculorum folitariae, inferiores magis acuminatae. Bracteae tres fubrotundae albidobyalinae, concavae, quarum extima major, floris bafin veltiunt calycis loco

CAL。 nullus。

cor. Monopetala, bafi cylindrica, profunde fexpartita, laciniis oblongis, obufis, revolutis。

stam. Filamenta fex fubulata, petali laciniis fea ce breviora. Antberae fagittatae, bali bipartitae.

pist. Germen fuperum, conico - ovatum, glabrum, apice poris tribus perforatum. Stylus fubtrigonus corolla paullo brevior. Stigma trigonum fimplex.

PER. Bacca irrgulariter globofa, trilocularis po* lyfperma, nigra.

SEM. aliquot, arillo pulpofo involuta, vt quafi vnum videantur, in quovis loculamento.

Varietas $\beta$ purpurea foliorum venas, petiolos, pedunculos et flores purpureos habet. Terminalis domeltica alba et purpurea, nec non angufifolia Rumph. Amb. IV. p. 79.8I. tab. 34. 35. omnes hune fpectant. Idem celeberrimus auctor radicem huius ra caenae contra Diarrhaeas et Dyfenteriam praeftantifimam laudat, quum vires potius in edulcorando et obtundendo quam in confringendo exferat. Incolis infulae o- Taheiti cibum praebet. Folia apud incolas infulae Ternate $\mathrm{Ng} a / \sqrt{2}, i$. e. mendacia vocantur, quia binos colores, viridem nempe et purpureum exhibent; eadem fi alicui mittuntur, illum pro mendaci declärant. Apud indigenas autem infularum in oceano paa cifico huius plantae folia paffin amicitiae et pacis figna ac pignora funt. Diis ibidem facra habetur, et in 
inprimis ad coemeteria et aras colitur. Taheitice $T$, five $T i b i$ i. e anima.

\section{IV. \\ O L E E R A.}

33. DRACAENA INDIVISA. F.

D. arborea, foliis enfiformibus auctis, ra. cemo (laterali?) compolito. F.

Haecce arbor, cum proxime fequentibus, Areca oleracea et fapida, Apio graveolente, Tetragonia halimifolia, Lepidio oleraceo et pifcidio, atque Soncho oleraceo inter praeftantiflimas plantas elculentas in terris auftrafine merito recenferi debet; licet eaedem vix ab incolis et indigenis vfurpentur; fed Europaeis, maxime poft longinquum iter maritimum Scorbuto laborantibus, faluberrima olera praebeant.

Haec Dracaenae fpecies nafcitur in fylvis ad portum Novae-Zeelandiae, auftralioris, cui nomen obfcuri (Dufkybay) Cookius dedit, in fcopulis mari faepé proximis. Ejus baccae ni fallor ab incolis comeduntur: folia autem tenella convoluta, feu potius hybernaculum arboris ex apice trunci prodiens, pedale, inter folia reconditum, albo flavercens, blandum, medullofum, cum oleo et aceto inter optima acetaria jure habetur. Baccae inenfe maio five hyeme ineunte maturefcunt. In temperatioribus Novae 'Zeelandiae regionibus circa aeftuarium Reginae Charlottae, altera Dracaenae fpecies'reperitur, quam heic praetcrmitto, eum eius in re cibaria vfus nobis non innotuerit, 
Caulis arboreus, teres, rimulolus, fimplicifimus, indivilus, virens verfus apicem foliis veltitus, bi feu tri-orgyalis.

Folia terminalia ferilia, femiamplexicaulia, bafi imbricata, late enfiformia, membranacea, acuta, integerrima, patentia, longidinaliter ftriata, laete virentia bipedalia, palmum lata.

Racemus componitus, lateralis ex alis foliorum (fed forfan folia jam feriora, feu fecundi anni, prodierant), ovatus nutans, racenis partialibus in fomam cylindricam thyrloideam digefis. Pedunculus uni. verfalis bi-feu tripedalis, reres, laevis, herbaceus, diametrolfefquipollicari: partiales fpithamei approximati, ereck-patentes, teretes, laeves, bafi inlructi foliolo lanceolato, pedunculi longitudine; undique fparIme pedunculo univerfali prodeuntes. Pedicelli uniflo. ri, breviflumi, horizontales. Bracteae ad bafin pedicelli duae, minimae, lanceolatae, acutas, concavae.

Car. nullus.

cor. Petala fex oblonga, fubreflexa, aequalia, bafi cohaerentia.

STAM. Filamem fex, fubulata, fere longitudine petalorum, eorunque bafi inferta. Antberas oblongae, incumbentes.

prst. Germen fuperum. Stylus filiformis breuis. Stigma. - -

PFr. Bacca globola, caerulea, fupra punfis tribus excavatis notata, ftylo perfiftente mucronata, trilocularis, polifperma. 
SEM. in fingulo loculamento circier feptem, arillo Seu membranula involuta * ut unicum crederes, atra, glabra, femilunaria, triquetra.

OBS. Character genericus Dracaenae in hasce duas fpecies D. terminalem Linu et $D$. indivifan no. Aram non perfecte quadrat, quum harum baccae plane polyfpermae fint, quas tamen trifpermas charadter genericus iuxta noviffimam Syftematis Linneani Editionem XIVtam p. 3II. 333. requirit. Forte haec nota D. Draconi foli competit; vel etiam pro unico femine habebatur arillus feminibus farctus. Anne effentialis differentia inter Afparagi, Dracaenaeque genera in hocce arillo confiftit?

34. areca oleracea. Linn.

A. foliolis integerrimis $M S . V$ p. $996 . \mathrm{n} 2$.

Hanc arborem femel vidimus in hortis infulae Tanuae, fed tum temporis neque florentem, neque fructus proferentem. Veri tamen fimillinum eft, eandem propter fructuum ad rem cibariam ufum $a b$ incolis cultam fuiffe. Eius gemma ficut praecedentis Dracaenae et omniuin palmarum, edulis eft, dulcis et delicatula, tanquam braficae caules teneriores, aut $C_{\text {ynarae receptaculum. Ob def clum florefcentiae }}$ eandem ulterius examinare non potuimus; ad hanc fpeciem amandandam effe, ex Cel. lacquini defcriptione conclufinus.

35. ARECA SAPIDA. Solander.

A. - -

Reperitur fpontanea in nova Zcelandia usque ad aeftuarium Charlottae reginae. et frequens in Norfolciae infula deferta. Huius praecipue Cor five Caput 
in deliciis eft apud nautas Europaeos, et cum oleo et aceto parari folet. Nomen a b. Solandro matuati fumus, cum neque fructum neque Horefcentian huius palmae examini nofro fubicere nobis datum effet. Huius furte generis eft Nits -gula, (Cocos rubra), Palma, cuius Cooḱius meninit in Tonga infula, it bmeris novifuni tomo 1. p. 332.

36. APIUM GRATEOLENS, LINR.

A foliis cauinis cuneiformibus. M. S. $V_{\text {. }}$ P. 292。

Abundat in novae Zeelandiac littoribus; legitur etiam in Pafchatis infula, nec non intra tropicos in infulis demeris, fponte proveniens, incolis quantum fcio, inuftatum, natis vero fcorbuticis gratiflumus et maxime falutare.

37. TETRAGONIA HALIMIFOLIA. F.

T. herbacea, papulofa, folios ellipticom thombeis petiolatis, pedunculis axilla ribus uniloris fubfolitaris, freat cornuto. $\mathrm{F}$.

Habitat in Nova Zeelandia ad oras fylvarum in plagis fenticolis er arenofrs, mec non intra tropicos in. littore infulae Tongatabu. Incolis inufitaca, fed in. ser olera praefantifina collocanda. Infu enim in mortalis Cookii dun in portu moraremur, çuotidie pro ientacalo et prandio cocta natitis apponebatur. Tota planta confperfa eft puncis minutifmis cryftallinis, quales in Atriplice, Chenopodis, Mefembry. anthemisque nomnullis obfervantur, unde papulofa vel etiam rorida uici poffet. Defcriptionem in folo matali confcriptam non prorlus fupervacancan fore 
arbirror, licet hanc noftram cum $T$ expanfa M. S. V. p- 467. n. 6. pro eadem fpecie declarare vix dubitem.

Caulis herbaceus, laevis, procumbens, ramofus, ftrii elevatis e marginibus petiolorum decurrentib subangulatus, penna anferina parum craffior, debilis. Rami plures elongati, teretes, patentes.

Folia alterna fubpetiolata, ovato - rhombea, obtufiufcula, integerrima, horizontalia, internodiis breviora, fefqui-pollicaria. Petioli tenues fupra planiufculi, pollicares.

Pedunculi fubfolitarii axillares uniflori breviffimi. Flores flavi.

CAL. Perianthium quadri - rarius quinque partitum, laciniis fubaequalibus ovatis, fubacutis, intus coloratis, una reliquis latiore magis rotundata.

COR. nulla.

stam. Filamentn fedecim vel duodecim fubulato - capillaria, calyce breviora. Antbor is fubrotundae didymae, ereeto incumbentes.

pist Germen minimum. Styli fex, rarius quinque, filiformes, decidui, fubreflexi, longitudine ftaminum. Stigmata fimplicia.

PER. Drupa rudis, turbinata, five obverfe co. nica, carnofa, verfus apicem tetragona five penta. gona, angulis productioribus acutis cornuta.

SEM. Nux offea, loculamentis numero ftylorum refpondentibus monofpermis. Nuclei folita. rii, ovati, albi. 
38. LePIDIUM OLERACEUM F.

L. foliis/elliptico-oblongis acutis ferratis, floribus tecrandris. F.

Habitat in Novae Zeelandiae littori arenofos inprimis ad aeftuarium Charlottae, locis dumofis fubumbraticis. Cum Apio et Tetragonia halimifolia quotidianum olus nautarum erat, dum in hoc portu commorati fumus. Inter alimenta antifcorbutica nunquam fatis laudandum, faporis blandi, paullulum acris, ad fpinachiae vel etiam lactucae faporem accedentis, paullo flatulentum, alvun modice aperiens.

Caulis perennis, herbaceus, teres, laevis, erecto-adfcendens, ramofus, ramis paniculatis, a pedali faepe in femorgyalem altitudinem excrefcens.

Folia fparfa, alterna, elliptico-oblonga, utrinque attenuata, profunde ferrata, patentia, glabra, palmaria; fuperiora minora, apice tantum ferrata. Petioli ( $f$ hoc nomine malis vocare folii partem inferiorem anguftiorem) foliis dimidio brevioris, plani extrorfum carinati, caulem excipientes.

Pedunculi univerfales terminales, teretes, laeves, aphylli; Racemi fimplices, fub inflorelcentia coarctati, corymbof, fructiferi palmares, cylin. drici. Pedicelli plurimi, fparfi, filiformes, teretcs, patentes, femipollicares, uniflori. Flores albi, bilineares.

CAL. Perianthium tetraphyllum deciduum, foliolis fubrotundis concavis, patuli; , extu-fubpubeicentibus.

cor. Petala quatuor fubrotunda integra, concava, calyce duplo maiora, ungue lineari lamina dimidio breviore.

E 3 STAM 
sтam. Filamenta quatuor, aequalia, fubnata erecta, longitadine fere corollae. Antherae fubglobofae flavae.

PIST. Germen avatum. Sty? cylindricus breviff: mus, perfiftens. tigmu obtufun.

per. Silicula ovato - cordata, compreffa, bilocularis, bivalvis, valvulis navicularibus, monofpermis, diffepimento lanceolato.

SEM. folitaria, ovata, acuta, flavorubentia.

39. LERTDIUM PISCIDIUM. F.

L. foliis elliptico oblongis, acutis integerrimis: floribus tetradynamis $F$.

Habitat intra tropicos in infulis demerfis, etiam in Huaheine et in Botanices infula ad novam Caledoniam adjacente. Incolis ufui venit ad pifces inebriandos et capiendos; nobis tamen inter acetaria apnoni folebat, acerrimumm. Simile praecedenti, fed multis notis effentialiter diffinctum.

Caulis herbaceus bipedalis, ramis patentiadfeendentibus, teretibus, laevibus.

Folia alterm, elliptico-ablonga, acuta, integerrima, patentia, laxa, bipollicaria, inferiora caulis bafi attenuata, elongata fere petiolata.

Racemi terminales, folitarii, fimplices. Pedunculus univerfalis teres, laevis, erectiufculus, binalmaris. Pedicelli fparfi, fliformes, patentes, corymbor, laeves, uniflori, bilineares. Flores parvi.

caz. Periantbirm tetraphyllum, foliolis concavis, ovalibus, erefiufeulis, intus albicantibus. 
єor. Petala, quatuor aequalia, alba, fpatulata calyce longiora, anguftiora, cum eius foliolis alternantia.

Nectarium e glandulis fex minutis compreflis viridibus, ftaminibus interjectis.

stam. Filamenta fex fubulata longitudine calycis, horum duo, carinis germinis opopofita paullo minora. Antberas minutae.

PIST. Germen oblongum, compreffum, utrinque carinatum. Stylus cylindricus breviffimus. Stigina fimplex excavatum.

PER. Silicula ovalis, comprefía, apice emarginata,bilocularis, valvulis navicularibus compreffis, carinatis.

SEM. fubfolitaria, ovata, apice attenuata, pedicello minimo valvularum apici adfixa.

40. SONCHus oleraceus. Linn.

S. pedunculis tomentofis, calycibus glaw bris. M.S. V. p. 712. n. 5.

Reperitur in Nova Zeelandia et in amicorum in. Sulis, fatis frequens. Ejus caules tenelli et folia juniora pro acetariis a noftratibus ufurpari folebant.

4I, BOERHAAVIA ERECTA. Linn.

B. Caule erecto glabro, floribus diandris. M. S. V.p. 52 .

Caules plerumque procumbentes et in hac fpecie, ufurpantur $\mathrm{ab}$ incolis infularum $\mathrm{o}$ - Taheiti et Societatis, fi carior fuerit annona, et oleris loco comeduntur, licet vix aliquid faporis habeant. Planta fylvatica, fponte proveniens. Taheitenfbus Nunв - nunв。 


\section{SOLANUM VIRIDE. Solander.}

\section{S. - - -}

Huius fpeciei mentionum injecit Parkin/on (Foum p. 38). Folia inter olera colta five affata comeduntur. Planta fponte proveniens, apud incolas vocatur Purabeitio

43. Portulaca lutea, S.

P. - - -

Herba fimillima $P$. oleraceae, diftinguenda tamen fi Parkinfonio credas, qui nomen a $b$. Solandro huic fpeciei impofitum, tradidit in Journ. 1- c. Mihi femel, at fine florefcentia in Huaheine occurrit. Crefcit in littore infularum Societatis et demerfurum, quae lithophytorum fabricae incumbunt. Cokta ab incolis oleris loco comeditur, et apud Taheitenfes nomine Aturi diftinguitur.

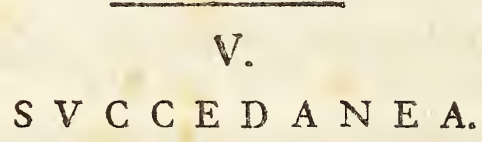

44. AVicennia resinifera. F.

A foliis lato-lanceolatis, fubtus tomen. tofis. F.

Arbor. Specimina noftra ante florum eruptionem lecta, cum A. refinifera Solandri in herbario Bankfiano contuli, et eiusdem fpeciei effe refcivi.

Folia oppofita, petiolata, lanceolata, coriacea, integra, acuta, fuperius nitida, fubtus tomento breriffmo, flavicante incano, bipollicaria. Petioli brevifimi femiteretes, extrorfum rugofi, erectopatentes. 
Pedunculi terminales fubtrifidi, capitulo florum onufti. Gummi ex hac arbore exfudans forte idem eft, quo barbari novae Zeelandiae homines vefcuntur, ut patețe diario navarchi gallici Crozet, p. 67.

"Je leur ai vu manger une efpèce de gomme „de couleur verte, dont ils paroiffent faire grand „cas. Je n'ai pu favoir, de quel arbre ils la tiennent. "Quelquesuns de nous en ont mangé, en la faifant "fondre dans la bouche; nous l'avons tous égale"ment trouvée d'une qualité très-échauffante,"

\section{HiBiscys TILIACEvs. Linn.}

H. foliis cordatis fubrotundis indivifis acuminatis crenatis, caule arboreo, calyce exteriore decemdentato $M . S, V$. p. 620. ก. II.

Calycis nota ad dignofcendam hanc fpeciem praeftantiffima eft. Folia enim variant, aut fimpliciter cordatafere orbiculata; aut in tres, quinosve angulos acutos excurrentia; pubefcentia vel nuda; profunde crenata vel integerrima; majora, vel minufcula. Flores fulphurei, ampli, bafi faturate purpurei, petalis fubrotundis, unguibus oblongis.

Reperitur paffim intra tropicos in littore infularum Societatis, Marchionis, Amicorum, novarum Hebridum et novae Caledoniae. Cum artocarpi meffis deficiat, Taheitenfes huius Hibifci corticem exfugunt : novae Caledoniae autem homines faepius hoc alimento infulfo ac minime nutriente vefcebantur.

E 5 46. Coix 
46. COIX LACRYMA. Linn. M. S. V́. p. 842。

Semina huius graminis dulcia funt et edulia. Reperta a nobis eft in Tongatabu et E. uwa, Ámicorum infulis: nefcio an cultis ibidem adnumeretur.

47. Pteris Lsculenta. F.

P. frondibus fupradecompofitis fulcatis, foliolis pinnatis, pinnis linearibus decurrentibus, fummis brevioribus. $F$.

Reperitur in fylvis infularum Societatis. Radices ab incolis inop bus et famelicis exfuguntur, infipidae, parum nutrientes lignofo-fibrofae.

Frondes fupradecompofitae, triplicato-pinnatas, mximae, radicales glabrae, ftipite fuperne fulco exmato, divifuris omnibus alternis, univerfalioribus interdum oppofitis.

Foliola pinnata, circiter bipollicaria, pinnis linew aribus integerrimis obtufis, margine revolutis, coriaceis, approximatis, decurrentibus, inferioribus discretis, hinc inde dentatis, feu pinnatifitis, extimis fenfim brevioribus.

Fructificationis lineae marginales fere totum dise cum occupant, membranula tenui femina vix obtegente.

Taheitenfibus e N Narrd.

48. POLYPodum MEDULLARE. F.

P. frondibus bipinnatis: foliolis pinnatis acuminatiffimis: pinnis oblongis fubfalcatis acutis, crenatis, flipite afpero, caudice arboreo. F.

Haee filicis fpecies in fylvis Novae Zeelandiae Erequens eft, et apesd incolas Mansagg dicitur; hi radicers 
dicem et caudicis inferioris medullam toftan comea dunt; huius enim fubftantiae mollis et pulpofae fapor quandam fimilitudinem cum rapae fapore labet, et quidem huic praeftat, ita ut ad medullam Saguari ar: boris accedat. In medullari fubftantia huius polypodii fuccus glutinofus, rubefcens abundat.

Caudex orgyalis, fpongiofus, fubftantia medullari farclus, extrorfum hifpidus, nigricans, e cafu fipitun, apice frondibus maximis horizontaliter tere patentibus coronatus. Frons decompofita, orgyalis et ultra, ftipite tuberculis feu punctis callofis exiguis, rubicundis undique afpero. Foliola conferta, pinnata, inferiora bipollicaria, angufta, acuminatiffima, Pinnulae omnes feffiles, oblongo-lunatae, acutae, infimae difcretae, crenatae, fuperiores fenfim brevio. res connexae, ut apex folii plane ferratus fit, ferra. turis profundis acutis.

Fruclificationes globofae, maiufculae, in difco, fimplia ferie.

\section{POLYPODIUM DICHOTOMUM.}

$P$. frondibus dichotomis bipinnatis : pinnulis linearibus integris, parallelis. Thunb: $f$, jap.p. 338. t. 37. M. S. V.p. 038. n. 66.

Sponte crefcit in montibus aridis Novae Zeelandiae, nec non intra Tropicos, in collibus aridiffmis infularum Societatis, Radice fuper igne torrefacta es lapide vel fulte conquaflata vefcuntur novae Zeelandiae homines, exfugendo partem farinofam, dulces. centem. Defcriptio $\mathrm{Cl}$. Thunbergii, qui eandens plantam in laponia legit, optime quadrat. 


\section{$\frac{2 \cos ^{2}}{\sin \sin ^{2}}$ \\ $\mathrm{VI}$. \\ POTULEN T A.}

50. PIPER Methystrcum. F.

P. foliis cordatis acuminatis multinerviis: fpicis axillaribus foltariis breviffimis, pedunculatis, patentifimis. $F$.

Species cante difinguenda a Pipere latifolio quod in Supplem. plantar. p. 9I. nefcio quo cafu Piper methyfticum vocatur. Etenim non folum notis botanicis plurimis a vero Pipere methyltico, latifolium illud difcrepat, fed etiam toxica qualitate caret, neque in hunc ufum ab incolis unquam adhibetnr, fponteque nafcit per omnes fere infulas oceani auftralis intraltropicos. fitas.

Piper methyficum verum inter plantas cultas earundem infularum paffim reperitur, iis tamen exceptis, quae nigrae gentis fedes funt, novis Hebridibus et Caledonia nova. Inter plantas auten cultas harum regionum non alia maiori cura et follertia, neque tam adfidius laboribus colitur, quam haec ipfa piperis perniciofiffina fpecies; nam et folum huic culturae idoneum ligonilus crebro fubvertitur, et a herbis, fponte nafcentibus liberatur, fimulque calce e coralliis et conchis marinis tatifcentibus, fercoris loco fecundatur. Radix contufa vei potius manducata, et cum faliva humectata, fuccum praebet naufeofo fervidum, cui affunditur liquor e nucibus Cocos, vel etiam aqua pura. Liquorem fic paratum acrem, nat?feofum, virefcentem harum infularum proceres et facrificuli in deliciis habent; quo minore aquae portione commifcentur pocula, eo pluris exiftimantur, citius enim inebriant et in fomnum refolvunt; nimis frequenter antem repetitun temetum țotus corpus ficco 
ardore quafi accendit. Tum oculi rubere, cutis exarefcere et in fquamulas exfoliari, quae tandem in ulcera leprofa degenerant, vel univerfam corporis ma-ciem tabemque praefaginnt. Sapor huins liquoris omnium maxime ingratus, ipfis pertinacifimis potator:bus óra difforquet atque membra quatit horore. (Cook in itin. novif. Vol. 1. p.318.). Vires videntur ineffe etian narcoticae. Nomen apud Taheitenfes: $A v a$, apud incolas infularum Amicorum et Sandvigiarum cum afpiratione dura praefixa: Kava. Caulis plerumque orgyalem altitudinem attingit dichotomus, maculofus, Folia oblongo - cordata, nec ut in P. latifolio fubrotundo - cordata. Spicae rectae breves folitariae, nec aggregatae, longae, nutantes. Perfectam florefcentiam non vidimus.

5I. Saccharum officinarum. Linn.

S. floribus paniculatis, foliis planis, (lanum. gine flofculis longiore F.) M.S. $V_{0}$. p.103. n. 2.

Huius graminis magna copia plantatur in campis 2xidis infulae Pafchatos, cuius incolae ob aquae penuriam, eiusdem culmos dulci fueco plenos exfugunt. In O-Taheiti, Societatis, Marchiorum, Amicorum, Sandvigii infulis minus frequens, cultum tamen nee fponte proveniens, infantibus et pueris relinquitur, Taheitenfium $T_{0}$.

52. Convolvulus tURPETHUM. Linn.

C. foliis cordatis, angulatis caule membranaceo quadrangulari, pedunculis multifloris. M. S. D. p. 201.n. 22。

Sponte in infulis Societatis, Amicorum, Novarumque Hebridum nafcit. Caules fucco dulcefcente abundant, taheitenfiun pueris grato. Apud Parkin- 
fonum (Journ. p. 37.) vocatur Convolvulus alatus; Anne jure, a C. Turpetho feparetur, videant illi quibus fequentem defcriptionem cun vero C. Turpe. tho Linnaei comparare licebit.

Radix brevis, digiti craffitie, emittens fibras fpic thamea longitudine, fibrillis paucis.

Caules tetragoni, membranulis alati.

Folia cordata, obtufiufcula, interdum angulata, palmaria Petioli femiteretes, folio dimidio breviores.

Pedunculi teretinfculi, palmares, trifidi, pedicellis fubunifloris. Flores albi, corollis calyce vix duplo longioribus, campanulatis, plicatisque, quinquefidis.

Calycis foliola duo exteriora ovata villofa, reliquis duplo majora, (Hinc forte Linnaeus in Flora Zeylanica, p. $3 \mathrm{x}$. fingulo flori involucrum diphylJun tribuit, ) tria interiora ovata glabra.

Antherae fpirales! Stigma globofo bilobum. Capfula membranacea, globofo-depreffa, bilocularis, loculamentis I. f. 2. fpermis. Semina fubcotunia, hinc angulata, atra, obfcura.

Nomen Taheitenfe Taudibau.

53. melaleuca scoparia. F.

M. foliis alternis ovatis acutis fubtrinerviis floribus terminalibus folitariis feffilibus. F.

Melaleuca fcoparia M. S. V. p.699. n. 40 Leptofpermum fcoparium. Forft. Charad. gen. 36.

Haec arbufcula Novae Zeelandiae vix locum heic meruiffet, nifi eius llores et ramuli floriferi recentes, 
folis tenellis onuti ab Europaeis Cookium comitantibus in itineribus fuis circa globum terraqueum et ad autralesinfulas, pro infufo, in Theae locum, adhibitaefuifent. Potus hicce fuaviter aromaticus, fragrans, brevi amen nimium amarorem contrahebat, fcorbuticis ad inflaurandam valetudinem non nihil forte proderat.

Caulis arboreus, ramofifinus, erectiufculus, rimofus, cinereus, ramis diffufis, obliquis, fubfaltigiatis, teretibus, aphyllis, fummis virgatis foliofis, apice herbaceis, villofo-fericeis.

Folia alterna fparfa, fubfeffilia, ovato- lanceolata, acuta integerrima, trinervia, patentia, plana, laevia, punctata, fupra intenfe viridia fubtus pallida, bilinearia. Petioli vix ulli, planiufculi.

Flores folitariiterminales, fefiles in apice ramulorum, albi, magnitudine florum cerafi. Bracteae fub. rotundae, imbricatae, concavae, deciduae calycem ufque ad medium cingentes, obtegentes.

Cal. Periantbium, hemifphaericum, germini adnatum, idque umbilicans, margine integerrimo elevato. Limbus e foliolis quinque parvis, ovatis, concavis, cum petalis alternantibus, albis, extus rubia cundis, deciduis.

COR. Petala quinque orbiculata, patentifima, pla: niufcula, ungue minimo calycis margini interiori inferta, ejus foliolis triplo longiora.

stam. Filamenta vigintiquatuor, erecta, fubulata, petalis dimidio breviora, calycis margini fumplici ordine inferta. Antherae didymae, fubrotundae.

PIST. Germen hemifphaericum, calyce umbilica. sum, inferiusque veftitum, fupra convexiufculum. Stylus filiformis, longitudine et directione ftaminum deciduus, Stigma capitatum.

PER。 
pre. Capfula haemifphaerica, calyce umbilicata, fupra planoconvexa, apice puncto excavata, quinque frriata, quinquelocularis, quinquevalis, apice dehifcens, polyfperma. nuifima.

SEM. plurima, minima, linearia, cylindrica, te.

OBs. Haec fpecies a Charactere generico Melaleucae aliquanto recedit, fed tamen eidem generi adnectitur perfpeciem intermediam, nempe M. virgatam.

\section{DACRYDIUM CURRESSINum. Solander.}

Pulcherrimum hocce 'Taxoque affine genus, cuius florefcentiam non vidimus, ab Illuntri Solandro nomen Dxcrydii accepit. Reperitur in Nova Zeelandia, vbi Cookius, e junioribus ramufculis, foliis tenellis onultis, et refinofa materia amaricante featentibus, potum, cerevifiae quodammodo fumilem, parari jube. bat, cuius praeftantian in malo fcorbutico difertis verbis extollit in hodoeporico \& fuccedaneum potumcereuifiae e taleis Pini canadenfis confecti, inque America fepten. trionali \& inter nautas notiflimi, vulgo Spruce - beer effe voluit. Non tamen negandum eft, hunce Dacrydio cupreflino paratum potum, jejunis nauleam et vertiginem nduxifle, parvo temporis fpatio interjecto tranfeuntem.

Benevole lector, Pauca fphalmata, qux lectin difficilem red, dere poffent fic corrigere velis.

Pag. 8. Lin. 8. pro labis lege labiis. p. 9. 1. 21. p. crafrciuseula 1. craffiuscula $p^{15}$.1.26. p. diofcoreaa. 1. diofcoreae. p.19. Not. r. p. in 1. id. p. 20. 1. 13. p. granatum 1. Granatum. p. 23.1 ro. p. efibrillis 1. e fibrillis. p. 28.1. 21. p. ccrnuntur. 1. cernuntur. 1, 29, 1.3. p. onginquo 1. longinquo. p. 32.1. 8. p. geri I. gerit, p. 32.1.24. p. reigx 1. regix. p 37.1 . 19 p. Arbo 1. Arbor. p. 40.1.12. p. cuneate 1. cuneatae. $p_{0} 4$. p. in habitantium 1 . inhabitantium 1.52 .1 .20$. p. eollocantur 1 collocantur. p. 58.1 .35 p. fingnlis. 1. finzulis. p. 60.1. 6. p. hexaphillum 1. hexaphyllum. p. 6r.1. 1. p. poftit 1. poffie. p. 61. 1. 13. p. radices 1. radicis. p. 62. 1. 14. p. emitit 1. emittit. p. 63.

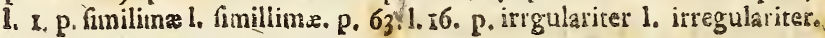




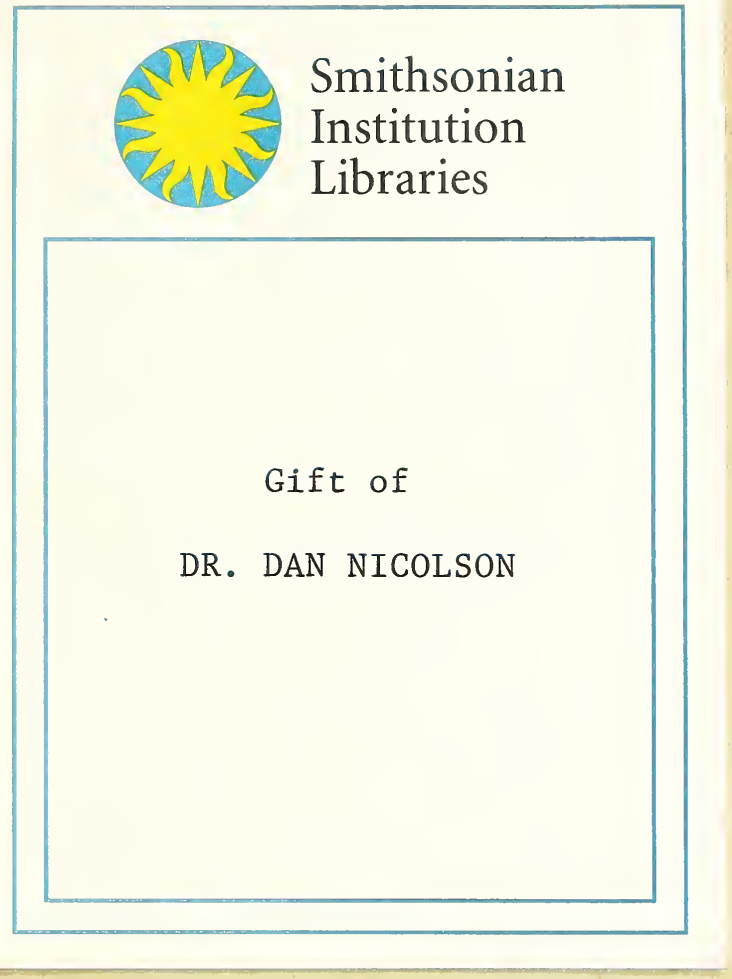




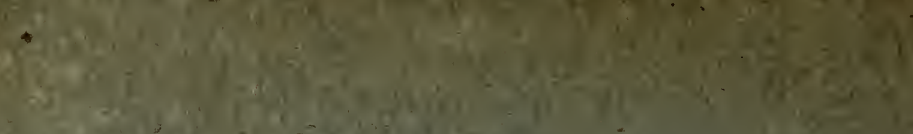

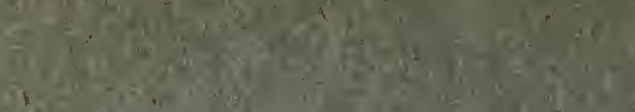

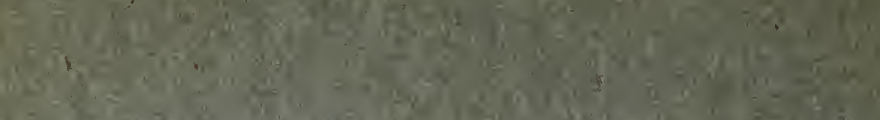

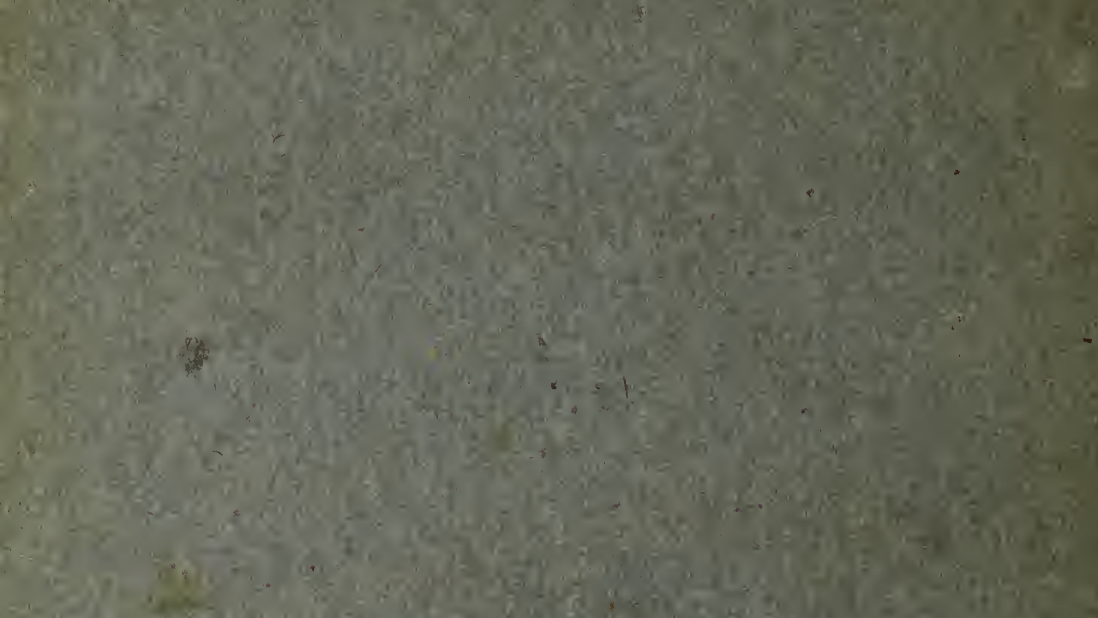

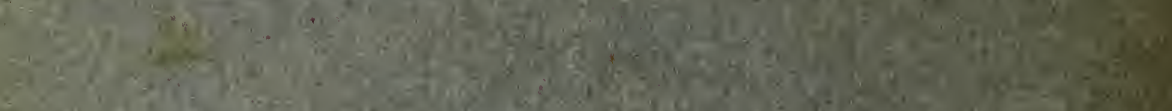
and

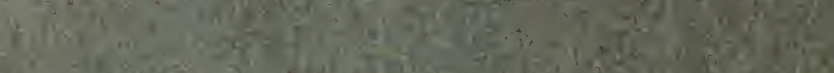

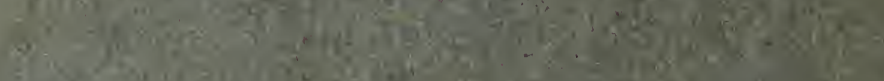

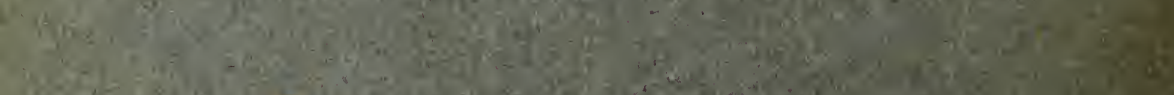

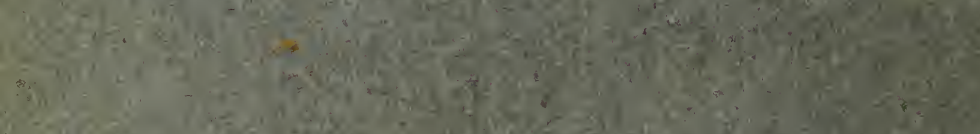

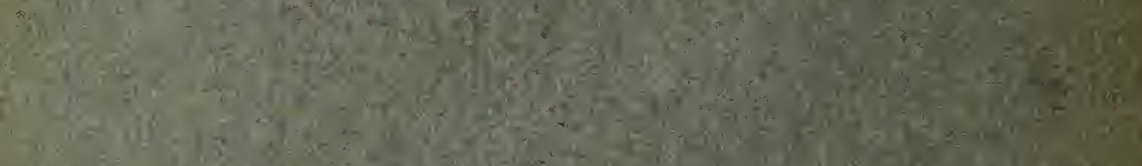

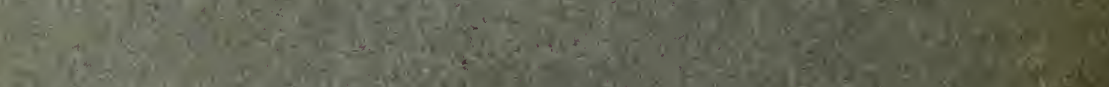

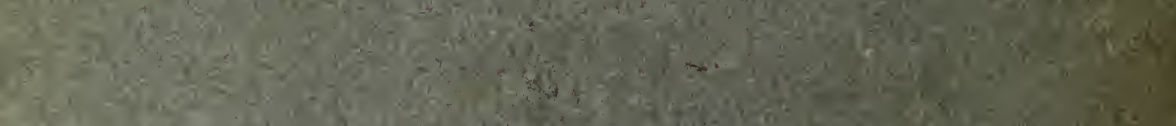

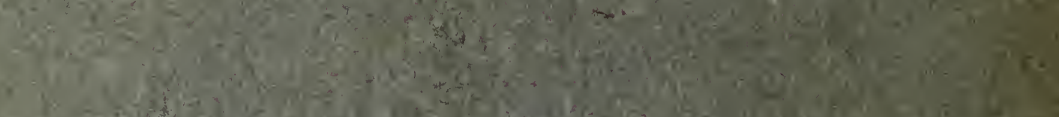

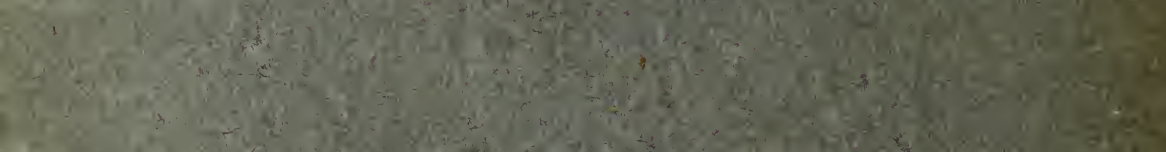

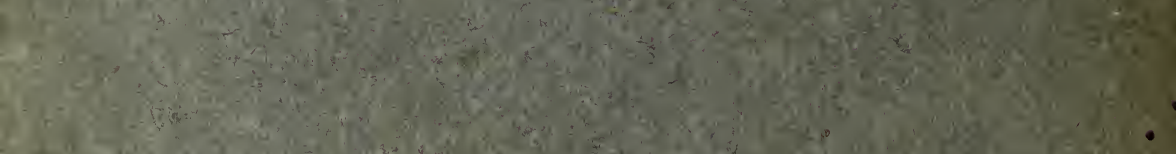

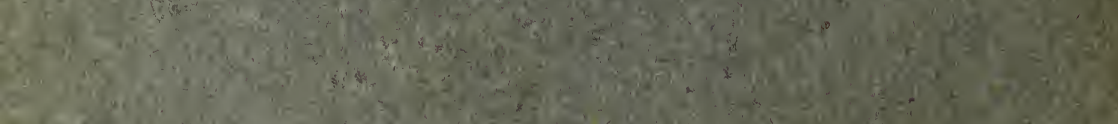

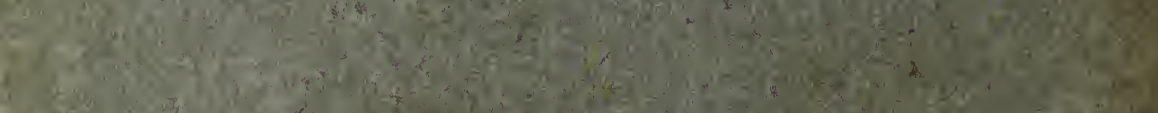

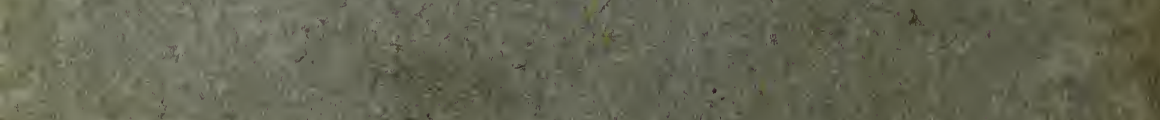
(3)

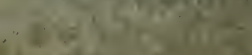

